\title{
LA INFLUENCIA DEL CONSTITUCIONALISMO FRANCÉS EN LA FASE DE INICIACIÓN CONSTITUCIONAL ESPAÑOLA $(1808-1834)^{1}$
}

\author{
POR \\ JOSÉ MANUEL VERA SANTOS \\ Profesor Titular de Derecho Constitucional. \\ Universidad Rey Juan Carlos
}

\section{INTRODUCCIÓN CONCEPTUAL Y METODOLÓGICA: EL CONSTITUCIONALISMO HISTÓRICO ESPAÑOL}

El constitucionalismo español se nos presenta marcado por dos conceptos básicos a partir de los cuales podemos intentar su explicación: la inestabilidad constitucional y por una serie de rasgos definidores $^{2}$.

${ }^{1}$ Este artículo ha sido elaborado dentro del Proyecto de Investigación del Plan Nacional de Investigación Científica, Desarrollo e Innovación Tecnológica "La influencia del constitucionalismo europeo en la historia constitucional española» (BHA 2000-0406), cuyo investigador principal ha sido el Profesor González-Trevijano.

2 Seguimos en este punto la opinión de De Esteban, J. Tratado de Derecho Constitucional. Madrid: Facultad de Derecho de la Universidad Complutense de Madrid, 1998, pp. 14 y siguientes. En el estudio previo a GARCíA FERNÁNDEZ, F. J., EsPíN TEMPLADo, E. y De Esteban, J. (dir). Esquemas del constitucionalismo español. Madrid: Facultad de Derecho de la Universidad Complutense de Madrid, 1976, encontramos, junto a valiosas aportaciones, una brillante síntesis doctrinal. Sigue 


\subsection{La inestabilidad constitucional}

Que España presenta una, absolutamente cierta, inestabilidad constitucional no debe argumentarse en exceso, si bien Francia la supera en este aspecto $^{3}$. Desde el Estatuto de Bayona de 1808, pasando por la Constitución de Cádiz de 1812, el Estatuto Real de 1834, las Constituciones - liberal la una, moderada la otra- de 1837 y 1845, la Constitución democrática de 1869, la de la restauración canovista de 1876, la dictadura primorriverista de 1923, la republicana de 1931 y las leyes fundamentales franquistas, numerosos textos $-\mathrm{y}$ variados contextosconstitucionales jalonan nuestros procelosos siglos XIX y XX, hasta la entrada en vigor del actual texto de 1978 cuyo vigésimo séptimo aniversario acabamos de conmemorar ${ }^{4}$.

igualmente esta teoría, aportando importantes sugerencias propias y de otros autores, Fernández Segado, F. Las Constituciones históricas españolas. Madrid: Civitas, 1986, pp. 50-55.

Además de las anteriores, citamos como obras más destacadas y que nos sirven de base general de este estudio las siguientes: SÁNCHEZ AGESTA, L. Historia del constitucionalismo español. Madrid: Instituto de Estudios Políticos, 1974; FrAILE CLIVILLES, M. Introducción al Derecho Constitucional Español. Madrid: 1975; SOLÉ TURA, J. y AJA, E. Constituciones y periodos constituyentes en España. 1808-1936. Madrid: Siglo XXI, 1977; TOMÁs VILLAROYA, J. Breve historia del constitucionalismo español. Madrid: Centro de Estudios Constitucionales, 1981 (ed. 1987); Fernández Segado, F. Las Constituciones históricas españolas. Madrid: Civitas, 1986; TORRES DEL MORAL, A. Constitucionalismo histórico español. Madrid: Átomo, 1.986 (ed. 1991); MerINo MeRCHÁN, J. F. Regímenes históricos españoles. Madrid: Tecnos, 1988; CLAVERO, B. Manual de historia constitucional de España. Madrid: Alianza, 1989; CAVERo LATAILLADE, I. y ZAMORA Rodríguez, T. Constitucionalismo histórico español. Madrid: Universitas, 1995; NúNEez Rivero, C. y Martínez Segarra, R. M. Historia constitucional de España. Madrid: Universitas, 2002. Vid. Ias páginas preliminares de SÁnCHEZ AgeSTA y FERnÁNDEZ SeGADO (pp. 17-44 y 27-55, respectivamente), donde encontramos de manera somera una presentación básica del constitucionalismo español del siglo XIX, sus causas e influencias.

3 Comienza Tomás Villaroya la introducción a su obra, con estas palabras: "Cuando se aborda el estudio de nuestra historia constitucional, el primer dato que, de manera inmediata, se impone a los demás es el número de Constituciones que España ha conocido. España, después de Francia, es posiblemente el país europeo que ha hecho, rehecho y deshecho mayor número de Constituciones" (o. c., p. 9). TORRES Del Moral (o. c., p. 16) no sólo destaca dicha inestabilidad sino que va más allá, identificando bajo la misma "una relativa continuidad de la economía y de los presupuestos ideológicos de la clase política».

${ }_{4} \mathrm{Ni}$ que decir tiene que, como veremos al estudiar, por ejemplo, el Estatuto Real, hubo tres intentos de reforma; lo mismo se observa respecto al texto de 1845. También han de citarse el proyecto de 1873 primero-republicano, y los variados re- 
Este hecho denota que nuestros "padres de la Patria» no supieron dotarse de una norma fundamental que asumiera jurídicamente las necesidades, las demandas sociales y, además, las llevara a la práctica, creándose así un claro divorcio entre el "ser» y el "deber ser». En puridad, y consecuentemente, la inestabilidad en la norma esencial conllevó que tanto el buen gobierno (desde medidas políticas concretas hasta la institucionalización de aquellos poderes diferentes a la Corona), como el desarrollo y protección de los derechos y libertades ciudadanos quedaran siempre en situaciones, cuando no excepcionales, de una gran tibieza aplicativa. En suma, la clase política pensaba más en subvertir el sistema que en consolidar y perfeccionar el existente ${ }^{5}$.

Como causas de la meritada inestabilidad constitucional se indi$\operatorname{can}^{6}$ : a) la aparición desfasada del régimen constitucional en España, ya que su nacimiento aparece vinculado en un primer momento a la situación revolucionaria francesa y, posteriormente, a la invasión napoleónica; b) la ausencia de una revolución burguesa en España hizo que el movimiento constitucional fuese interpretado como extranjerizante y sin raíz social que lo defendiera: las estructuras arcaicas del Antiguo Régimen, seis años de guerra contra los franceses, la pérdida de la mayor parte de nuestras colonias, son hitos que produjeron que apareciese

gímenes "de hecho» como el del general Serrano hasta el advenimiento de Alfonso XIII. En fin, trúfese el pastel con las dos Regencias de amplia duración (hasta que Isabel II y Alfonso XIII alcanzaron la mayoría de edad), más otras variables internas como la inestabilidad ministerial, o el fenómeno del pronunciamiento militar, y concluiremos con un absoluto convencimiento de que la estabilidad no es una característica de nuestro constitucionalismo.

${ }^{5}$ Es muy conocida la cita de un Gautier que, cuando visitó España y observó sobre un edificio de granito una placa intitulada "Plaza de la Constitución», exclamó: "Eso es una Constitución en España: una pellada de yeso sobre granito», aludiendo así al carácter mudable y contingente de nuestro primer constitucionalismo y a la existencia de una realidad socioeconómica y política granítica, resistente, que siempre subyacía y permanecía inmutable (SÁNCHEZ AgESTA o. c., pp. 22-23). Contundente TORRES DEL MORAL (o. c., p. 17) al afirmar que "a la postre, la política transcurrió siempre al margen de los textos constitucionales. Alguna Constitución no pasó de proyecto, otra no fue promulgada, ninguna fue cabalmente aplicada, varias tuvieron una muy corta vigencia y todas una vida zozobrante. Incluso sólo eran aplicadas, cuando lo eran, en las grandes ciudades, y salvo en Madrid, casi siempre estaban suspendidas sus garantías por los capitanes generales".

6 Vid. De Esteban (o. c., pp. 14-23). Tomás Villarroya (o. c., p. 10) destaca que la inestabilidad constitucional se debe, sobre todo, a la consideración de la Constitución como obra de parte, de facción, de partido, además de a los efectos beneficiosos casi inmediatos que del texto se predicaban; al no cumplirse las expectativas, nuevamente comienza el círculo. 
antes la consecuencia jurídico-política (el constitucionalismo) que la causa social (la revolución burguesa) ${ }^{7}$; y c) difícilmente podrían nuestras Constituciones dotar de estabilidad a una Nación desarticulada y sin organización administrativa estatal que la soportara: las tendencias regionalistas (en la actualidad nacionalistas) o la sagrada unión dual entre Administración y oligarquía, con la consiguiente falta de profesionalización de los servidores públicos y el sistema de "los cesantes", que tan bien retratara y sufriera Larra, potenciaban un sentimiento patrimonialista del Estado y, por ende, de la Constitución, que aparecía, más que como marco de entendimiento, como un instrumento de poder de la ideología predominante.

\subsection{Rasgos característicos del constitucionalismo español}

En segundo término, junto a la inestabilidad constitucional, aludíamos a la existencia de una serie de rasgos característicos del constitucionalismo español, unos caracteres que pueden ser internos o externos al propio texto constitucional ${ }^{8}$. A ello vamos a continuación.

\subsubsection{Rasgos internos}

El primero de los rasgos internos al que se alude es la falta de originalidad de nuestros textos constitucionales, rasgo éste que nos allana el camino para el estudio objeto de este trabajo, porque es el constitucionalismo francés uno de los que más influye en los primeros momentos del constitucionalismo español ${ }^{9}$. Esta falta de originalidad

7 SÁNCHEZ AgESTA considera no obstante que la presencia de la burguesía en el siglo XIX sí se hizo notar en el fenómeno político, desarrollando el constitucionalismo como "revolución de las clases medias", sin ese matiz violento de nuestro vecino de los Pirineos (o. c., pp. 24-30).

8 Hemos de advertir que esta clasificación, como ya indica el autor de la misma, se refiere, por un lado a los rasgos más directamente vinculados al conjunto de nuestras Constituciones; por otro, encontramos los rasgos que se deducen de los textos constitucionales del entorno, sin olvidar que los unos influyen en los otros, por lo que su clasificación no debe ser óbice para observar su importancia, además de que se aluden no sólo a cuestiones estrictamente constitucionales, sino que entran en el ámbito de lo social, económico o político. Vid. De EsTeban (o. c, p. 23).

9 Del examen de los textos del constitucionalismo francés, y de los propios españoles, siguiendo a la mejor doctrina hemos de concluir que el constitucionalismo francés ha sido especialmente influyente en los albores del devenir constitucional 
no sólo es causa del influjo foráneo, sino que conlleva también que nuestras Constituciones presenten una fuerte dependencia de los anteriores textos patrios.

El otro de los rasgos internos que destacamos consiste en la excesiva carga ideológica que presentan nuestras Constituciones, la estrecha relación de las mismas con ideologías, a veces casi banderías, concretas, dando lugar a "Constituciones de partido", parciales, con tendencia desde su génesis a olvidar las reclamaciones de los contrarios. Esto conllevaba, evidentemente, que, cada vez que había un cambio de gobierno, se pretendiera reformar alguno o varios de los aspectos regulados constitucionalmente que, a lo largo de nuestra historia, han sido objeto de conflicto. Así, por ejemplo la ubicación de la soberanía (nacional en 1812, 1837, 1869, 1931; compartida en 1834, 1845, 1876), al que aparecen vinculados otras cuestiones como la separación de poderes, aplicada más por las Constituciones liberales citadas que por las otras cuatro moderadas; la declaración de los derechos fundamentales (sobre todo la libertad de imprenta y la religiosa), o el sufragio, censitario o universal. Muy vinculada también al concepto de soberanía aparecerá la discusión sobre la forma de jefatura de Estado, entre Monarquía y República, bien que ésta última sólo obtuviese éxito en su reconocimiento en dos textos de nuestra historia constitucional (en el Proyecto de 1873 y en la Constitución de 1931), no siendo tampoco modelo de concordia y de sentido institucional.

español. Más concretamente, y dejando a un lado el carácter español o no del Estatuto de Bayona, van a ser en las Constituciones de 1812, el Estatuto Real de 1834, la Constitución liberal de 1837 y la moderada de 1845 los textos que son recipiendarios de la práctica constitucional francesa. Seguimos en este punto la opinión, por todos, de De EsteBAN (Tratado, o. c. pp. 37-39). En el resto de nuestros textos constitucionales se encontrarán algunas otras influencias francesas, buscadas o no, pero mucho menos significativas. La presencia de un régimen monárquico prevalente en España, frente al cambio en el siglo XIX francés en lo tocante a la Jefatura del Estado; el continuo uso de la institución de la Regencia en ese siglo español y el consiguiente influjo en el reparto y concentración de poder; las diferencias sociales, económicas y políticas, pérdida de las colonias incluidas, hace perfectamente comprensible el porqué de la postrer separación institucional entre los regímenes de Francia y España. Igualmente, la salida del sistema absolutista hacia el liberalismo y las continuas idas y venidas de las diferentes corrientes políticas liberales y conservadoras propias de ese primer momento, hace que la influencia encontrada se sitúe en puridad en el momento procesal adecuado, que no es otro que los albores del sistema liberal. Considera igualmente esta influencia francesa en los textos españoles indicados, por todos, FERNÁNDEZ SEGADO (o. c., p. 51, nota 132), bien que excluye el texto de Bayona, al no considerarlo como texto constitucional español. 
Lo mismo ha de indicarse sobre la forma territorial del Estado, con movimientos regionalistas, tamizados de carlismo y nacionalismo irracional; términos como confederación, pacto con la Corona, federación, son fieles acompañantes de la historia de España y también se observan en sus Constituciones, bien que sólo se plasmasen, desde el punto de vista constitucional-institucional, en los textos de 1873 (non nato) y de $1931^{10}$. Y qué decir de la importancia del concepto de soberanía al ser aplicado en el modelo organizativo de las Cortes, de la representación nacional: la lucha entre monocameralismo y bicameralismo, entre independencia del legislativo y fuerza del mismo frente a influencia de la Corona y mixtificación de sus funciones. En fin, y todo ello marcado por una Monarquía cuyo protagonismo ha estado fuera de toda duda, acertando unas veces, errando otras.

\subsubsection{Rasgos externos}

Como rasgos externos identificadores de nuestro constitucionalismo encontramos la falta de arraigo de las Constituciones y su exigencia taumatúrgica, además de una especie de separación entre el proceso político y lo expresado en la Constitución. Del "vivan las cadenas" de los españoles a la llegada de Fernando VII, hasta la decisión impuesta a este Monarca de "caminemos juntos, francamente, por la senda constitucional» no sólo pasan pocos años y algún levantamiento (1820), sino una manera de entender el constitucionalismo visto "desde arriba», por las clases dominantes, muy alejadas de la mayoría de un pueblo que se encontraba absolutamente alejado de la realidad política. Quizás por eso ya el artículo 368 de la Constitución de Cádiz abogase porque se enseñase la Constitución (eso sí, a los estudiosos universitarios), que tan clara era esa separación popular de un sistema constitucional que, aún hoy, debe ser explicado muy profundamente si queremos que nuestras próximas generaciones no sólo sean demócratas por el fantasma del pasado franquista, sino convencidas de las bondades de un sistema del que nos servimos para contener un poder que siempre tiende a ser absoluto. El desconocimiento del significado del constitucionalismo, decíamos, junto a la separación de las clases po-

10 El profesor DE ESTEBAN, autor a quién seguimos tanto en esta parte introductoria como en las fases de desarrollo constitucional que se proponen, establece que la Monarquía y el regionalismo suponen los dos sustratos básicos del constitucionalismo español. Así lo hace constar en Las Constituciones de España. Madrid: CEPC, 1998, pp. 21-26. 
pulares de la toma de decisiones (sufragio censitario o, en un postrer momento, falseamiento del sistema electoral con el turno de partidos de la Restauración) ${ }^{11}$, hicieron también prosperar una idea taumatúrgica, milagrosa de lo que era y significaba la Constitución; y cuando ese "bálsamo de Fierabrás", remedio mágico de nuestro D. Quijote, se veía que no cambiaba la situación general, la vinculación con el sistema iba olvidándose incluso por aquellos que fueron sus artífices. Algo similar ha pasado tras la caída del muro de Berlín en los países sometidos por la dictadura comunista, bien que poco a poco, el sistema democrático se impone frente al "miedo a la libertad".

En segundo lugar, como factor externo al texto constitucional, encontramos que el proceso político siempre aparece desvinculado de la propia Constitución; valga como ejemplo que únicamente la Constitución de 1845 fue aprobada siguiendo el procedimiento formal que el anterior texto de 1837 prescribía. Sin ánimo de exhaustividad, cabe recordarse el numeroso elenco de reformas, textos non natos o proyectos, amén de regímenes de hecho, que aparecen independientemente de los preceptos constitucionales, como ya hemos indicado, claro ejemplo del divorcio Constitución-realidad política.

Pues bien, debemos concluir que el constitucionalismo español, partiendo de la idea de soberanía y las implicaciones que ella conllevaba a la que hemos hecho mención, se debate en una especie de dicotomía entre liberalismo y moderantismo, acción-reacción que únicamente se ha sintetizado en el texto de 1978 actual. Así, generalizando y obviando proyectos y reformas variadas, frente a la acción liberal (1812), aparece la reacción moderada en el Estatuto Real de 1834; nuevamente vuelve el liberalismo en 1837, dejando paso al moderantismo en 1845, que a su vez observa como la Constitución democrática de 1869 vuelve a dejar su sitio al doctrinarismo canovista en 1876.1931 supondrá un fracasado intento democrático ahogado por el régimen fran-

11 Los pronunciamientos primero, el caciquismo y las manipulaciones del sufragio después, acaban transformando el sistema representativo en la farsa con que legaliza sus poderes una oligarquía. El régimen constitucional representativo acaba siendo un espectáculo de gran escenografía entre unos grupos políticos que hacen las Cortes y se apoyan en ellas. A fines de siglo este fenómeno se va a denunciar con toda su crudeza. "La realidad es esta —decía Maura en el año 1904—. La gran mayoría del pueblo español está abstenida, no interviene para nada en la vida pública». Y Costa repite machaconamente: "Farsa el sufragio, farsa el gobierno, farsa el parlamento, farsa la libertad, farsa la Patria» (Vid. SÁNCHEZ AgeSTA, o. c., p. 23). A esa desafección Constitución-ciudadanía también se refiere TOMÁs VILLARROYA (o. c., p. 10). 
quista. De ahí que diferenciemos temporalmente una serie de fases en el constitucionalismo patrio en las que se observa -exceptuando la tercera de ellas-, la dialéctica de "las dos Españas", el moderantismo y el liberalismo. En primer término encontramos la fase de iniciación constitucional, que ocupa desde el texto de Bayona o la Constitución gaditana de $1812^{12}$ hasta el moderantista Estatuto Real de 1834; Ios textos -liberal y moderado de 1837 y 1845 ocupan la fase de reafirmación del movimiento constitucional en España; en tercer lugar encontramos la denominada fase revolucionaria con una Constitución democrática en 1869 y el Proyecto federal-republicano de 1873; la doble restauración monárquica y republicana que suponen el texto doctrinario canovista de 1876 y la II República española, da paso a una quinta fase autoritaria que, una vez superada, culmina con la fase de normalidad constitucional que simboliza el texto constitucional de 1978, en tanto Constitución de todos y para todos ${ }^{13}$.

En este trabajo estudiamos la influencia de los textos franceses en la fase primigenia del constitucionalismo nacional (Estatuto de Bayona, Constitución de 1812 y Estatuto Real de 1834), haciendo especial hincapié en el aspecto institucional, organizativo, de un poder político que evoluciona desde criterios absolutistas hacia un sentir liberal. Pero hemos de advertir que, metodológicamente, al tratarse de observar la influencia del constitucionalismo francés en los textos hispanos, partimos de éstos últimos para cotejar aquella, de tal forma que acudiremos en numerosas ocasiones a la utilización de notas a pie de página para precisar matices de un argumento básico que figura en un texto principal, intentando así simplificar el mismo para posibilitar su mejor lectura. Igualmente cabe destacarse que, en esta obra, intentamos realizar un cotejo normativo, testando con el mismo las opiniones doctrinales y la literalidad de los diversos articulados estudiados.

Con carácter general se ha de indicar que, para una más amplia comprensión de los textos concretos y del constitucionalismo francés en general, se puede consultar nuestro estudio sobre Las Constituciones de Francia (Valencia: Tirant lo Blanch, 2004). Igualmente se utiliza esta obra para comprobar el articulado constitucional, siendo especialmente destacable dicha consulta si el lector no se encuentra familiarizado con el idioma francés, ya que los textos también se encuentran traducidos al castellano.

12 Según los autores incluyan o no la Constitución de Bayona entre los textos constitucionales propios.

13 Vid. nuevamente De Esteban (Las Constituciones de o. c., pp. 10-42). 
Vocación -y casi obligación- ésta de consultar los textos que, en estos momentos atribulados en los que la interpretación sistemática "pro parte" se impone a la correcta y necesaria lectura del articulado constitucional, puede resultar — como siempre, como se enseña en los primeros cursos de las Facultades de Derecho, como la propia razón indica- enormemente clarificadora. Quien quiera escuchar, que lo haga.

\section{EL ESTATUTO DE BAYONA, DE 6 DE JULIO DE 1808}

\subsection{Introducción. Parte dogmática}

El General Murat marchaba sobre Madrid, cuando se produjo el llamado motín de Aranjuez en marzo de 1808, siendo proclamado Rey Fernando VII por un pueblo que conocía que Carlos IV y el valido Godoy intentan huir de España. Posteriormente, el 2 de mayo, el alcalde de Móstoles, entonces un pequeño pueblo de las afueras de Madrid, redactaba un bando que circuló por España alertando sobre el peligro que se cernía sobre la Patria, animando así el rescoldo de un espíritu nacional que se forjaría en sus enfrentamientos con el invasor. Estos acontecimientos conllevan una serie de renuncias al Trono que Napoleón aprovecha para convocar a toda la Familia Real española en Bayona, mientras que nombraba Rey de España a su hermano José Bonaparte (6 de junio) ${ }^{14}$.

14 Respecto al "cuadro histórico" previo a la invasión francesa (instituciones del Antiguo Régimen y eficacia de las mismas o el enfrentamiento ente Godoy y el Príncipe de Asturias, por ejemplo), y el episodio de la instauración de la nueva dinastía en España, vid. SANZ CID, C. La Constitución de Bayona, Madrid: Editorial Reus, 1922, pp. 7-39 y 40-56. Hacemos nuestras las palabras de este autor, tan citado como poco consultado, referidas a que, en su época -y quizás también en la nuestra- no existía un estudio detenido de la Constitución de Bayona, más allá de aquél de Pierre Conard. También apoyamos los motivos que esgrime: "Los tratadistas de la pasada centuria, dominados aún por el vivo sentimiento de indignación y protesta que provocó la invasión napoleónica, lejos de esclarecer y estudiar los actos políticos del Gobierno intruso, les confunden en una común execración con las violencias de la conquista, para guardar íntegro el homenaje de su recuerdo para las épicas hazañas de la independencia». Esa es la confusión más común. Estudiar el Estatuto de Bayona, aún sabiendo de su nula aplicación y de su origen extranjero, consideramos es absolutamente necesario para tener una imagen cierta de la evolución de nuestro constitucionalismo; mucho más, como es el caso, si se estudia la influencia francesa en el mismo. 
Con la finalidad de legitimar la nueva situación, contestada en la caIle con continuos levantamientos populares, el Emperador francés convocó en Bayona una Asamblea de Notables españoles ${ }^{15}$ conformada estamentalmente y en una relación paritaria entre nobleza, clero y representantes populares, en razón de cincuenta individuos por cada uno de los grupos, si bien únicamente acudieron a Bayona la mitad del centenar y medio de miembros convocados, siendo la mayoría del cuerpo de la nobleza. Revisado por el propio Emperador, se aprobó un texto por esta asamblea, siendo promulgado el 6 de julio de $1808^{16}$. En pura lógica política e institucional, se observará en el Estatuto de Bayona una gran influencia de los textos constitucionales imperiales napoleónicos, sobre todo de la Constitución de 1799 (año VIII) ${ }^{17}$.

15 Destacan NúÑez Rivero y Martínez Segarra (o. c., págs 44-48) cómo esta Asamblea de Bayona, también denominada Junta Nacional o Junta Española, no gozaba de carácter representativo, además de las aportaciones de sus componentes al texto definitivo. Cf. respecto a éste último aspecto SANZ CID (o. c., pp. 204 y ss., referidas a la participación en la tramitación del Estatuto de la opinión de los miembros de la Junta y otros órganos. Vid. igualmente los apéndices que figuran al final de la obra meritada, tales como el informe del Consejero de la Inquisición o el de la Diputación del Consejo de Castilla).

${ }^{16}$ El Estatuto de Bayona estuvo, pues, en vigor desde julio de 1808 hasta principios de 1814, fecha en que las últimas tropas francesas cruzan los Pirineos, bien que va a coexistir en tiempo y lugar con el régimen absolutista existente y la renovación liberalizante del mismo que, primero las Juntas locales y provinciales y luego la Central, además de la Regencia, daría sus frutos en el texto de 1812. FERNÁNDEZ SEGADO expresa cómo la vigencia real del Texto de Bayona fue insignificante: en julio de 1808 se produce la batalla de Bailén con la derrota del ejército de Dupont y el comienzo del declive napoleónico en España. De idéntica opinión respecto al papel del Estatuto, por defecto, SÁnchez Agesta (o. c., p. 55).

17 El 9 de noviembre de 1799 ( 18 de Brumario en el calendario republicano) un joven general corso, Napoleón Bonaparte, a quién sus victorias en Italia han devenido muy conocido, da un golpe de Estado, suprimiendo los Consejos existentes y creando un Consulado provisional de tres miembros, entre los que él mismo se encuentra, junto a Sieyès y a Ducos. Este Consulado provisional elabora una Constitución que entra en vigor en diciembre de ese año, suponiendo un profundo cambio en relación con los textos y principios constitucionales de los textos franceses anteriores. Para mayor conocimiento de los textos imperiales napoleónicos vid. VERA SANToS, J. M. Las Constituciones de Francia. Valencia: Tirant lo Blanch, 2004, pp. 192200, en concreto, respecto al texto de 1799, págs, 193-196. La Constitución francesa del año VIII carece de parte dogmática por vez primera en el constitucionalismo galo, y se basa en los principios republicano y de soberanía nacional, bien que este último se ve corregido por el sistema ideado por Sieyès de varios grados (comunas, departamentos y estatal) a la hora de ejercer el sufragio universal activo por aquellos ciudadanos varones mayores de veintiún años establecidos durante más 
El Estatuto de Bayona constaba de ciento cuarenta y seis artículos además del Preámbulo ${ }^{18}$, siendo el ejemplo tipo de carta otorgada decimonónica, ya que es el poder regio —en este caso auspiciado por la ocupación napoleónica ${ }^{19}$ - , quien concede al pueblo una serie de derechos y libertades, amén de un mayor control entre los diferentes poderes. En lo tocante a su reforma — si bien no establece procedimiento alguno, conformándose así como un texto flexible-, el artículo 146 la imposibilita hasta una vez celebradas las Cortes posteriores a 1820, congelando la misma por tanto durante más de ocho años, con la manifiesta finalidad de permitir el asentamiento del nuevo régimen.

Sin la existencia de una clara separación entre las partes dogmática y orgánica, y antes de entrar en el estudio de las instituciones, debemos mencionar que el texto de 1808 introdujo en España —bien que por la fuerza, y el fin no justifica los medios-, los principios básicos del pen-

de un año en territorio francés (arts. 6 a 14). Frente a la fuerte separación de poderes del texto de 1791, o la más débil del aprobado en 1793, nos encontramos con un modelo donde existe una absoluta predominancia del gobierno frente a un poder asambleario dividido. Así encontramos cuatro asambleas, bien que la mayoría de los autores sólo incluyen dentro del poder legislativo al Tribunado y al Cuerpo legislativo, calificando al Consejo de Estado como órgano de apoyo al Primer Cónsul, al igual que los ministros; por su parte el Senado - que no aparece referido bajo la rúbrica del poder legislativo en el texto constitucional-, es ese "gran elector" y conservador de la Constitución.

18 Respecto a los tres proyectos y el texto definitivo del Estatuto de Bayona, la influencia de los "informes de los españoles" y el peso del derecho constitucional patrio en la redacción definitiva vid. SANZ CID (o. c., pp. 166-416). Destacan especialmente los cotejos o concordancias que realiza el autor, artículo por artículo de los diferentes proyectos, y referidos al derecho español y a los propios franceses, en las páginas 174 a 203, 233 a 252 y 260 a 307, así como la recopilación de las enmiendas y últimas adiciones discutidas y admitidas por la Junta (pp. 385 a 416). Resume el autor citado: "la forma definitiva en que, al final de las varias etapas de elaboración, cristalizó el estatuto, conserva como predominante el carácter con que apareció en su primer esbozo, el de ser una transcripción de disposiciones entresacadas del derecho constitucional de la Revolución y del Imperio, en la que, a lo sumo, se habían recogido algunas referencias al carácter y tradición de los españoles, y más principalmente, a las circunstancias en que iba a instaurarse la nueva dinastía» (o. c., pp. 442-443).

19 Así, por la mejor doctrina ToRres del Moral (o. c., p. 29). En el breve Preámbulo de esta Carta otorgada se lee: «(...) Don Josef Napoleón (...). Habiendo oído a la Junta Nacional, congregada en Bayona de orden de nuestro muy caro y muy amado hermano Napoleón, (...) hemos decretado y decretamos la presente Constitución". (TIERNo Galván, E. Leyes políticas fundamentales (1808-1978). Madrid: Tecnos, 1984, pp. 15-26). 
samiento ilustrado, eso sí, destilados por el pensamiento pragmático y autoritario de Napoleón ${ }^{20}$. Así encontramos, de manera deslavazada, la libertad de industria, comercio y la supresión de privilegios comerciales (arts. 88 a 90); se suprimen las aduanas interiores (art. 116), y se igualan las contribuciones (arts. 117 y 118), potenciando la igualdad entre los diferentes estamentos y acabando con los privilegios nobiliarios, como también ocurre con el caso de la supresión y disminución de mayorazgos (arts. 135 a 139). La libertad personal, con el procedimiento de habeas corpus (arts. 127 a 132), la prohibición del tormento (art. 133), la inviolabilidad del domicilio (art. 126) o la libertad de imprenta -eso sí, suspendida hasta los dos años posteriores a la entrada en vigor del Estatuto según se lee en el artículo 145-, componen un catálogo de derechos que suponían indefectiblemente un paso adelante que los constituyentes doceañistas tampoco van a poder obviar ${ }^{21}$.

$Y$ es que, el Estatuto de Bayona supone un claro aldabonazo en nuestro primigenio liberalismo, debido a su carácter escrito y tendencia liberalizante, ejemplo que hubo de asumirse por quiénes querían oponerse desde dentro a la invasión napoleónica ${ }^{22}$.

20 Con SANZ CID (o. c. p. 448), consideramos que aparece en el Estatuto de Bayona un doble principio antagónico: afirmar el principio liberal de la separación de poderes y articularlo de manera autoritaria. De igual pensar es FRAILE (o. c., p. 211). TORRES DEL MORAL (o. c., p. 32) alude a un tercer aspecto: el corporativismo propio del Antiguo Régimen.

${ }^{21}$ La inviolabilidad domiciliaria (art. 76), la libertad personal (art. 77), el derecho de habeas corpus (art. 80) o la prohibición de tormento (art. 82) también son derechos que reconoce el texto francés de 1791, bien que de manera anárquica y dentro de un Título VII (Disposiciones generales) que sirve de contenedor de diversas cuestiones.

${ }^{22}$ SolÉ Tura (o. c., p. 12). De "estímulo» que impulsa el proceso constituyente gaditano hablan Torres del Moral (o. c., p. 32) o SÁnChez Agesta (o. c., p. 55), quien, en las páginas siguientes destaca la idea reformadora que sirvió a la propaganda de Napoleón: la regeneración de España. NúÑEz Rivero y MARTínez SEgARRA (o. c., p. 15) destacan que "la idea constitucional nace en España con un texto, una Carta otorgada, el Estatuto de Bayona, que no llegó a tener vigencia, pero que sin su existencia posiblemente no hubiera conocido la luz, al menos en 1812, nuestro primer texto constitucional exponente de la soberanía nacional, la llamada Constitución de Cádiz». Como destaca SANZ CID (o. c., p. 449) "la Constitución de Bayona hubiese sido quizá un ensayo aceptable para introducir en España las nuevas formas constitucionales, sin grandes conmociones (...)". Sin entrar en mayores polémicas, ha de constatarse que en el Estatuto de Bayona podemos encontrar determinados principios que se encontrarán presentes en el constitucionalismo español hegemónico del siglo XIX: «la soberanía compartida entre el Rey y las Cortes; la Constitución histórica de España; la Corona como eje y nervio del Estado; la mistificación de la represen- 


\subsection{Organización institucional}

\subsubsection{El Poder ejecutivo}

En cuanto a la organización institucional del Estatuto de Bayona, hemos de diferenciar entre el órgano fundamental del mismo, que tal era la Corona - regulada de manera dispersa a lo largo y ancho del texto constitucional ${ }^{23}-$, y el resto de instituciones que pivotaban a su derredor $^{24}$.

Nos encontramos ante una Monarquía limitada ${ }^{25}$ que, según establecía el artículo 2 , «(...) será hereditaria en nuestra descendencia di-

tación nacional mediante un Senado que no sirvió más que para perpetuar la representación corporativa estamental; la centralización administrativa según el patrón francés; la confesionalidad e intolerancia religiosas (...)». Así se expresa, refiriéndose a la no tan clara influencia de la Constitución gaditana en la práctica del constitucionalismo español del XIX, exceptuando el texto de 1869 -liberalismo democrático-, Varela Suanzes-Carpegna, J. "La Constitución de Cádiz y el liberalismo español del siglo XIX", en Revista de las Cortes Generales, n. ${ }^{\circ}$ 10, 1987, pp. 27-109 [108-109]. Cabría discutir si éstos principios se adoptan por influencia del texto de Bayona o si, antes bien, el mismo forma parte de una idea predominante en el suelo patrio y que posteriormente se afianza, que tal es la teoría de la Constitución interna que se defenderá por los partidos moderados.

${ }^{23}$ Desde el artículo 1 y su identidad Religión-Rey-Nación a los cuatro Títulos referidos expresamente a la institución monárquica (Título II: Sucesión a la Corona —arts. 2 a 7-; Título III: Regencia —arts. 8 a 20_; Título IV: Dotación de la Corona —arts. 21 a 24-; y Título V: Oficios de la Casa Real —arts. 25 a 26-), pasando por los numerosos preceptos que refieren las competencias del Rey, tal y como expresamos en el cuerpo de este trabajo.

${ }_{24}$ Así Merino Merchan, autor al que seguimos en esta cuestión, expresa cómo «el régimen político del Estatuto aparece ensamblado por varios órganos entorno a la Corona, eje de todo el sistema, siendo órganos complementarios del poder ejecutivo, encarnado en la figura del Rey: el Ministerio, el Senado y el Consejo de Estado; además le correspondía al Rey el poder legislativo hasta que se celebrasen las primeras Cortes». Y es que se piensa, con Cambacérès (Cónsul junto a Napoleón Bonaparte y Le Brun) que "si para deliberar hacen falta muchos, para actuar hace falta uno" (TURPIN, D. Droit constitutionnel, Paris: PUF, 1997, p. 286). FernÁndez SEGAdo (o. c., p. 61) incide en la idea napoleónica de fragmentar los órganos y reducir así su peso. ARTOLA considera por su parte que este Estatuto resulta enormemente influenciado por el senadoconsulto de 18 de mayo de 1804 (Constitución del año XII) que dio a Napoleón el título de Emperador (ARTOLA, M. La burguesía revolucionaria. 1808-1869. Madrid: Alianza, 1973, p. 18).

${ }^{25}$ Muy poco limitada, habría de decirse a la vista de la concentración de poder existente, si bien las vicisitudes sociales y la falta de vigencia de este texto de Bayona no permite la observación del posible desarrollo de las relaciones institucio- 
recta, natural y legítima, de varón en varón, por orden de primogenitura y con exclusión perpetua de las hembras (...)», regulando igualmente el caso de que esta descendencia no se produjese: ascensión al Trono de Napoleón y su descendencia o del resto de sus hermanos y descendencia. Se trata así de constitucionalizar una Monarquía napoleónica ${ }^{26}$ en todo caso, aprovechando las cuitas borbónicas y la inanidad del poder patrio, bien que los acontecimientos no fuesen por el camino marcado desde Bayona por Napoleón y la Asamblea de Notables.

En lo tocante a las competencias regias, no se contiene en el texto una lista tasada de las mismas. La explicación venía dada por el carácter angular de esta institución, de la que dependen el resto de los órganos de poder. Y es que el Rey nombra a los miembros del Ministerio, a los senadores que no lo sean por razón de ser Infantes de España, preside el Consejo de Estado, asume las competencias ejecutivas y de administración (art. 143), pudiendo incluso dictar decretos con rango de ley cuando las Cortes no estuvieran reunidas (art. 60) ${ }^{27}$.

El Rey nombraba y separaba libremente a los miembros del Ministerio (Título VI, arts. 27 a 31) en un número máximo de nueve carteras, definidas materialmente en el artículo $27^{28}$. Un secretario de Estado refrendaba los decretos expedidos por el Rey (art. 28). Cada uno de los ministros era el encargado de ejecutar las órdenes regias en su departamento, siendo responsables de ellas y de la ejecución de las mismas (art. 31) ${ }^{29}$. Y es que podemos señalar que, como en la Constitución francesa del año VIII, se diferencian en la de Bayona los conceptos de

nales y hasta qué punto el Monarca contaría con el resto de instituciones. Pero, no obstante, supone un avance respecto al régimen absolutista, al menos si los derechos y libertades pudieran actuar de freno de la actividad del poder.

26 Idéntico fin encontramos en los artículos 3 y 4 del senado-consulto del año XII.

27 Igualmente es competencia del Monarca nombrar los cinco senadores componentes del Consejo de Tutela (art. 20), el nombramiento del Director General del Tesoro (art. 121) o el de los miembros del Tribunal de Contaduría (art. 122), además de designar al Regente de entre los Infantes mayores de veinticinco años (art. 10) y a la persona que vaya a desempeñar la guarda del Rey menor (art. 19). Sobre el texto francés de 1799 (año VIII) y cómo es el Senado que allí se instituye y, a su través, el Primer Cónsul, quién procede a los nombramientos de las más influyentes magistraturas, vid. VeRA SANTOS (o. c., pp. 195-196).

28 El artículo 29 expresa que el Rey podría reunir a su conveniencia el Ministerio de asuntos eclesiásticos al de justicia y el de policía general al de interior, pasando así de nueve a siete ministerios.

29 Régimen muy similar al que establecen los artículos 54 y 55 del texto francés del año VIII. 
gobierno, desarrollado por el Monarca apoyado en los órganos consultivos, y el de ejecución, perteneciendo ésta a los ministros ${ }^{30}$.

\subsection{2. Órganos de apoyo al Poder ejecutivo: El Senado y el Consejo de Estado}

En el Estatuto de Bayona aparece el Senado como Cámara que sirve de apoyo a un Monarca que ejerce directamente el poder ${ }^{31}$. Si bien la

${ }^{30}$ En el texto galo referenciado, el gobierno correspondía al Primer Cónsul apoyado en el Consejo de Estado y el poder ejecutivo a unos ministros que eran nombrados por aquél. En los artículos 39 a 42 observamos cómo el Primer Cónsul goza de una serie de competencias exclusivas (entre ellas, la iniciativa legislativa o el poder reglamentario), siendo los ministros los responsables de la ejecución. Compartimos así las opiniones de LóPEZ GUERRA, L. "La posición constitucional del Gobierno", en Gobierno y Administración en la Comunidad de Madrid. Madrid: IEF, 1988, p. 20 y de MENÉndez REXACH, A. La Jefatura del Estado en el Derecho público español. Madrid: INAP, 1979, pp. 150-155. Si el Monarca era la clave de la bóveda del Estatuto de Bayona, sin lugar a dudas, el órgano vital del sistema del texto constitucional francés es el Gobierno - término que utiliza la Constitución en vez del clásico "poder ejecutivo", y al que se refiere el Título IV del texto de 1799, en sus artículos 39 a 59-, compuesto por tres cónsules nombrados por el Senado por un mandato de diez años (el artículo 39 indica expresamente que, con carácter excepcional, el tercer Cónsul Lebrun sólo es nombrado por cinco años) e indefinidamente reelegibles (arts. 39 y 20). Destaca de entre ellos con una preponderancia absoluta, el Primer Cónsul, cargo que ocupa Napoleón Bonaparte, dotado en exclusiva de iniciativa legislativa; goza igualmente del poder reglamentario y vela por la ejecución de las leyes, cuida de la seguridad en general, ostenta el mando del Ejercito y nombra a sus oficiales, amén de poder superar el veto de las diferentes asambleas ante un proyecto de ley, bien de manera exclusiva o tras consulta a los otros cónsules, según se explicita en los artículos 40, 41 y 42. Los ministros, nombrados por el Primer Cónsul (arts. 72 y 73) son responsables de los actos que refrendan, de la inejecución de leyes y reglamentos y de las órdenes dictadas en contra de la Constitución, de leyes o de decretos, respondiendo ante una Alta Corte de Justicia compuesta por jueces y jurado. De "colegialidad de fachada" se califica este sistema en el que la supremacía del Primer Cónsul es más que evidente (BLUCHE, F. Manuel d'histoire politique de la France contemporaine. Paris: PUF, 2001, p. 92).

${ }^{31}$ Así se desprende de la falta de atribuciones legislativas y de la ubicación de este Senado en el propio Estatuto (Título VII, a continuación de la regulación de la Corona y del Ministerio; las Cortes unicamerales se regulan en el Título IX). Consideramos así que este Senado no sirve de precedente como órgano legislativo (vid. por todos, BERTELSEN RePETto, R. El Senado en España. Madrid: IEA, 1974, p. 501. De la misma opinión Colomer VIADEL, A. El sistema político de la Constitución española de 1837. Madrid: Congreso de los Diputados, 1989, p. 207. Se muestran también contrarios en su catalogación del mismo como órgano legislativo Fernández SegADo (o. c., p. 61), y De 
denominación es la de "Senado" no cabe caer en el error de considerarlo como una Cámara Alta conformadora, junto a las Cortes, del poder legislativo, pues sus competencias se limitan ordinariamente a la protección de la libertad de imprenta e individual (art. 39 en relación con los arts. 40 y 45 que establecen las Juntas senatoriales correspondientes encargadas de dicha protección), así como a garantizar la pureza electoral recogida en el artículo $51^{32}$. En cuanto a las antes mencionadas libertades de imprenta e individual encontramos la existencia de dos Juntas, de cinco miembros cada una, nombradas por el mismo Senado: A. La Junta senatoria de libertad individual, que controla el estado de las prisiones ejecutadas por la existencia de una trama conspiratoria contra el Estado de acuerdo con las previsiones del artículo 134; todas las personas presas y no puestas en libertad o llevadas a juicio después de un mes de prisión, podían recurrir directamente por sí, sus parientes o representantes, y por medio de petición, a la Junta (art. 41). B. La Junta senatoria de libertad de imprenta, que velaba para que los autores, impresores y libreros que hubiesen sido impedidos en el ejercicio de sus derechos, pudieran recurrir directamente y por medio de petición ante ella, bien que esta protección no incluía a los «papeles periódicos». En ambos casos, si las Juntas entrasen en colisión con los ministros que hubiesen mandado la prisión o impedido la impresión o publicación, y tras tres requisitorias consecutivas, el Pleno del Senado ponía en manos del Rey el asunto para que resolviese en consecuencia (arts. 43 y 48$)^{33}$.

De manera extraordinaria el Pleno puede proceder, previa propuesta por parte del Rey, a suspender el imperio de la Constitución por tiempo y lugar determinados en caso de existencia de sublevación ar-

Esteban (Esquemas del constitucionalismo o. c., p. 44). Por ejemplo, es conocida la cita de POSADA calificando a este órgano como "guardián y garantía de los derechos políticos" (Tratado de Derecho Político. Madrid: 1935, p. 270)

${ }^{32}$ El artículo 21 del texto francés del año VIII también prevé, dentro de ese control de constitucionalidad que realiza el Senado conservador, que se incluya el cumplimiento del proceso electoral. En el caso de Bayona, no se permite pues el control de constitucionalidad genérico por el Senado, pero sí el estudio del proceso electivo.

${ }^{33}$ La creación de las Juntas senatoriales y de la competencia de vigilar por la libertad individual y de imprenta en el caso francés, aparece con la reforma del texto del año VIII producida por el senado-consulto del año XII -1804- (arts. 60 y 64), con Juntas de siete miembros (las de Bayona también alcanzaban ese número con los dos suplentes, siendo el procedimiento a seguir muy similar al arriba mencionado). 
mada, amenazas al Estado o si fuese necesario para la conservación de la seguridad pública, tal y como reseña el artículo 38 del Estatuto ${ }^{34}$.

El artículo 32 por su parte denota hasta qué punto se produce una total sujeción de la composición de la Cámara senatorial a los intereses del Rey; dicho precepto indica que ésta se compondrá por los Infantes de España que tengan dieciocho años cumplidos y veinticuatro individuos nombrados por el Rey entre los ministros, los Capitanes generales del Ejército y Armada, los Embajadores, los Consejeros de Estado y los miembros del Consejo Real.

Excepto a los Infantes de España, se exige para poder ser nombrado senador haber alcanzado la edad de cuarenta años (art. 33), siendo su condición vitalicia salvo sentencia dictada por la Alta Corte Real (art. 34 en relación con los arts. 108 a 110). Además, de entre los senadores se elegían tanto los miembros del Consejo de Regencia (los siete más antiguos según reza el artículo 16), como los miembros del Consejo de Tutela (el artículo 20 indica que pertenecerían a la misma los cinco senadores que nombrase a tal efecto el último Rey o en su defecto los cinco senadores más antiguos). Igualmente los ocho senadores más antiguos pertenecen a la Alta Corte Real (art. 110) ${ }^{35}$.

34 Un artículo 38 que es trasunto del artículo 92 del texto francés de 1799 y similar al artículo 55 del texto del año $X$, si bien, en el caso español, es el Senado quien decreta la suspensión y en el francés se debe producir por ley.

${ }^{35}$ La introducción de un órgano que controlara la constitucionalidad de la normativa legal es una vieja idea de Sieyès (GUCHET, Y. Histoire constitutionnelle de la France 1789-1974. Paris: Economica, 1993, pp. 112-113 o MoRABITO, M. Histoire constitutionnelle de la France (1789-1958). Paris: Montchrestien, 2000, pp. 147-148). Este es el Senado conservador del texto galo de 1791, compuesto en un primer momento por sesenta miembros - posteriormente por ochenta, siguiendo el íter temporal que expresa el artículo 15, incrementando dos miembros cada año en los diez primeros-, mayores de cuarenta años (art. 15), y que es el competente para designar a los miembros de los otros órganos, aunque resultaba patente la sumisión de la institución senatorial a los designios del Primer Cónsul. Sus miembros son elegidos con carácter vitalicio, por cooptación sobre ternas propuestas por el Tribunado, el Cuerpo legislativo y el Primer Cónsul (art. 16), y presenta como funciones principales, alejadas en todo caso de las legislativas: a) la de elegir, como ya indicamos, entre otras magistraturas, a los miembros del Tribunado y del Cuerpo legislativo de entre la lista de confianza nacional (arts. 19 y 20); y b) la de velar por la constitucionalidad de las leyes, anulando cualquier actuación que le enviaran el Gobierno o el Tribunado y que atentaran contra el texto constitucional (art. 21). Como ya hemos indicado antes, merced a la reforma constitucional del año XII se crearon en el Senado galo los precedentes de los órganos senatoriales españoles encargados de velar por las libertades individuales y de imprenta Sobre la evolución normativa referida al Senado en los textos imperiales napoleónicos vid. VERA SANTOS (o. c., pp. 195-199).

(c) UNED. Revista de Derecho Político 
El Consejo de Estado de 1808 (Título VIII, arts. 50-60), con competencias consultivas (art. 59), era presidido por el Rey, estando compuesto por entre treinta y sesenta miembros (art. 50). Se encontraba dividido en seis secciones, siendo miembros natos los ministros y el Presidente del Consejo Real, pudiendo asistir a sus sesiones el Príncipe heredero una vez cumplidos los quince años (arts. 53 y 54). El resto de miembros eran libremente nombrados por el Monarca. Gozaba de competencias de orden legislativo, ya que examinaba, con carácter general, los proyectos de leyes civiles y criminales y los reglamentos generales de la Administración (art. 57). Excepcionalmente, y hasta que las Cortes no se convocasen, el Rey podía dictar leyes en materia de competencia de aquellas, siempre que contase con el voto favorable del Consejo de Estado (art. 60) ${ }^{36}$. En materia jurisdiccional, el Consejo de Estado conocía de asuntos entre cuerpos administrativos y judiciales, de asuntos contenciosos y citaba a los agentes de la administración pública (art. 58) ${ }^{37}$.

\subsubsection{El Poder legislativo}

Las Cortes o Juntas de la Nación (Título IX, arts. 61-86) —unas Cortes que como el Senado, nunca llegaron a ser constituidas-, se componían de ciento setenta y dos miembros, pertenecientes a los tres estamentos clásicos: nobleza - Grandes de Cortes "ex» artículo 63-, clero y representantes del pueblo (art. 61), debiendo ser convocadas

36 Importante competencia ésta ya que el Rey no se encontraba obligado más que a reunir las Cortes al menos una vez cada tres años (art. 76). Así lo destaca CLAVERO (o. c., p. 19).

37 En el texto de 1799 encontramos un Consejo de Estado cuyos miembros (en número indeterminado), son nombrados y revocados por aquél; este Consejo es el órgano encargado, además de asesorar al Gobierno, de elaborar y redactar los proyectos de ley. Dichos proyectos de ley eran defendidos por el Consejo de Estado ante el Cuerpo legislativo, junto a otros representantes del Tribunado (arts. 52 y 53). El Consejo de Estado derivado del senado-consulto del año XII (arts. 75 a 77) también gozaba de funciones consultivas, se encontraba dividido en seis secciones, sus miembros los elegía el Emperador y elevaban dictamen sobre los proyectos de ley y los reglamentos de la Administración, competencias que también indicaba el artículo 52 del texto del año VIII, incorporando también la resolución de las dificultades que se encontraran en materia administrativa, competencia que sí recoge, en cierta manera, el precepto español, perfeccionándola, al aludir al conocimiento de asuntos entre cuerpos administrativos y judiciales, asuntos contenciosos y citaciones a los agentes públicos. 
por un Monarca (art. 76) ${ }^{38}$ que, además, nombraba a su Presidente entre una terna que le presentaba la Cámara (art. 77) ${ }^{39}$.

Veinticinco nobles y otros tantos arzobispos y obispos, compartían escaño con sesenta y dos diputados de las provincias de España y de las Indias ${ }^{40}$; treinta diputados representantes de las ciudades principales de España y de las Indias; quince comerciantes o que tuvieran negocios y quince representantes del mundo universitario, la ciencia o las artes $\left(\right.$ art. 64) ${ }^{41}$.

Estas Cortes - cuyas sesiones no eran públicas ${ }^{42}$ y cuyas actas no podían publicarse, según prevén los artículos 80 y $81-$, no gozaban de una iniciativa legislativa que pertenecía en exclusiva al Rey, si bien se observa en el texto dos referencias a la capacidad legislativa de este órgano ${ }^{43}$. Según el artículo 82.2, debían someterse a deliberación y apro-

${ }^{38}$ El derecho francés, desde la época revolucionaria, abogaba por la autoconvocatoria de las asambleas (así, por ejemplo, los artículos 59 y 33 de los textos de los años III y VIII); sin embargo, el artículo 75 de la Constitución del año X establece un régimen similar al del artículo de Bayona estudiado.

39 Similar al régimen citado es el que presenta, de manera novedosa en el constitucionalismo francés, el artículo 8 del texto del año XII.

40 Muy singular la redacción del artículo 67 del texto de Bayona que apostilla los trescientos mil habitantes con un "poco más o menos". A efectos electorales, se dividen las provincias en partidos de elección con suficiente población para elegir un diputado; en los mismos se establece una Junta compuesta - hasta aprobación de una ley- por los decanos de los regidores municipales de municipios y por los curas de los pueblos principales del partido (arts. 67 y 68 ).

${ }^{41}$ En el caso del estamento nobiliario, para ser nombrados por el Monarca, debían disfrutar de una renta anual de veinte mil pesos fuertes o destacar por sus méritos civiles o militares (art. 66). Los representantes del pueblo llano resultaban elegidos por un mandato de tres años (art. 75). Los diputados provinciales eran nombrados uno por cada trescientos mil habitantes; los representantes de las treinta ciudades principales por los Ayuntamientos de cada una de ellas (art. 71), si bien, como en el caso anterior, se les solicita ser propietarios de bienes raíces (art. 72). Los representantes del comercio resultan elegidos entre los miembros de las Juntas de Comercio y entre los más ricos del Reino, siendo nombrados por el Monarca de entre una lista que presentaba cada uno de los Tribunales y Juntas de Comercio (art. 73). Los quince representantes del mundo de la cultura eran también nombrados por el Rey de entre listas presentadas por el Consejo Real —quince candidatos-, y las diferentes Universidades - siete candidatos cada una- (art. 74).

42 El artículo 35 del texto de 1799 declaraba, por el contrario, públicas las sesiones del Tribunado y del Cuerpo Legislativo.

${ }^{43}$ En el caso francés la iniciativa legislativa pertenece en exclusiva al Primer Cónsul — como se deduce de una interpretación lógica y sistemática de los artículos 39 a 42 - Por su parte el Tribunado se compone de cien miembros, mayores de vein- 
bación de las Cortes las reformas que se produjesen en materia referente al Código civil, penal o en materia impositiva; todos los proyectos de ley debían ser comunicados previamente por las secciones del Consejo de Estado -órgano consultivo-, a las Comisiones respectivas de las Cortes (art. 83). Además, en el plano de la legislación presupuestaria, ha de indicarse que correspondía a las Cortes la deliberación y aprobación cada tres años de las rentas y gastos anuales del Estado (art. 84), amén de examinar las cuentas anuales que debía presentar el ministro competente cada año ${ }^{44}$.

En cuanto a la capacidad de control político nos encontramos en el artículo 85 un primer paso en lo que podemos denominar responsabilidad -personal, eso sí- de los ministros a través de un procedimiento de queja motivada, que las Cortes elevan al Rey contra la actuación de un titular de un departamento, siendo ésta estudiada por seis miembros del Consejo Real y otros seis consejeros de Estado, bien que no se establece la consecuencia derivada de este procedimiento ${ }^{45}$.

\footnotetext{
ticinco años, elegidos por cinco años y renovables por quintas partes anualmente, siendo reelegibles con carácter indefinido (art. 27). En su seno se discuten los proyectos de ley, aprobando o rechazando los mismos (art. 28). La otra Cámara legislativa, denominada Cuerpo legislativo, está formada por trescientos miembros de una edad superior a los treinta años (art. 31). Escucha a los oradores del Gobierno, del Consejo de Estado y del Tribunado, votando el texto presentado sin posibilidad de discusión previa (art. 34). Sus miembros son elegidos de igual modo que el Tribunado, renovándose por quintas partes cada año (art. 31), si bien no son reelegibles inmediatamente (el artículo 32 indica que debe transcurrir al menos un año del cese), debiendo darse la circunstancia de que al menos tenga escaño un representante por cada departamento (art. 31). Podemos resumir con la doctrina francesa recordando que "el Cuerpo legislativo es un mudo que decide, mientras que el Tribunado delibera pero no decide" (Hamon, F., Troper, M. y Burdeau, G. Droit constitutionnel. Paris: LGDJ, 2001, p. 320).

${ }^{44}$ Respecto al procedimiento legislativo y las competencias de cada órgano en los textos napoleónicos y el de Bayona, no cabe hacer mayores comparaciones, ya que los sistemas institucionales son divergentes.

${ }^{45}$ El texto napoleónico de 1799 (año VIII) preveía en sus artículos 72 y 73 que los ministros, nombrados por el Primer Cónsul, son responsables de los actos que refrendan, la inejecución de leyes y reglamentos y de sus órdenes contrarias a la Constitución, leyes o decretos, respondiendo ante una Alta Corte de Justicia compuesta por jueces y jurados.
} 


\section{LA CONSTITUCIÓN POLÍTICA DE LA MONAROUÍA ESPAÑOLA DE 19 DE MARZO DE 1812}

\subsection{Introducción. Parte dogmática}

El pueblo de Madrid se alzó contra la ocupación de las tropas francesas el 2 de mayo de 1808, día en que los últimos miembros de la Familia Real partían hacia Bayona. A pesar de la resistencia popular, las tropas francesas se acantonan en Madrid y otras plazas como Barcelona o Pamplona. Los españoles constituyen Juntas de defensa local y provincial para organizar la resistencia contra Napoleón, coordinándose en una Junta Central Suprema en septiembre de 1808, pasando la ubicación de ésta, por los avatares de la guerra, de Aranjuez a Sevilla y, posteriormente, a Cádiz.

Esta Junta Central, cuya constitución sufrió numerosos avatares ${ }^{46}$, tuvo como principal preocupación convocar a Cortes con el fin de promulgar un texto constitucional patrio que enfrentar al impuesto por el Emperador francés. Igualmente nombró, antes de su disolución en enero de 1810, un Consejo de Regencia, compuesto por cinco miembros que se encargará de gobernar, hasta su venida, en nombre de Fernando VII. Es este Consejo el que finalmente procede a convocar Cortes ese mismo mes, con la aquiescencia de todos los sectores implicados, incluido el propio Rey, si bien existían diferentes tendencias sobre las competencias, naturaleza y fines a desarrollar por aquéllas ${ }^{47}$.

Los representantes fueron elegidos en verano de 1810 por los varones mayores de veinticinco años con vecindad en el distrito electoral,

${ }^{46}$ Vid. al respecto, Fernández Almagro, M. «Del Antiguo Régimen a las Cortes de Cádiz", en Revista de Estudios Políticos, n. ${ }^{\circ}$ 126, 1962, pp. 9-29 [12 y ss], autor que también reflexiona sobre como las Cortes no se convocaban en España desde hacía demasiado tiempo, hecho éste que probablemente hizo perder una oportunidad de reconducir, en el seno de las mismas, las reformas estructurales necesarias. Obsérvese el paralelismo con la falta de convocatoria en el caso de los Estados Generales en Francia, tal y como destaco en Vera SANTOS (o. c., p. 34). Vid. también TorRES DEL Moral (o. c., pp. 33-35) o Merino Merchán (o. c., pp. 37 a 41).

47 En la convocatoria de enero de 1810 se prevén unas Cortes estamentales en las que se reuniesen por un lado el pueblo y, por otro, las dignidades, preservando al menos formalmente las estructuras del Antiguo Régimen, tal como indica ComeLLAS ( "Las Cortes de Cádiz y la Constitución de 1812», en Revista de Estudios Políticos, n. ${ }^{\circ} 126,1962$, pp. 69-112 [75]). Decreto de 29 de enero de la Junta Central en SEVILLA ANDRÉs, D. Constituciones y otras leyes y proyectos políticos de España. 1808-1969. 2 vols, vol. I, pp. 81-85. 
recurriéndose al sorteo si la elección no se pudiese celebrar ${ }^{48}$. En septiembre de ese año se reunieron las Cortes como asamblea constituyente $^{49}$, según se puede leer en el Decreto de constitución de Cortes de 24 de ese mes $^{50}$, un decreto que supone ordenar los principios básicos que servirán de parámetro para la postrer obra constituyente: reconocimiento de la soberanía nacional y la legitimidad de la reunión de las propias Cortes; el reconocimiento como Rey de Fernando VII; la opción por una separación de poderes en virtud de la cual el legislativo pertenece a las propias Cortes y el ejecutivo a la Regencia, manteniendo provisionalmente a los tribunales existentes ${ }^{51}$. Las posiciones liberales ganan la primera y decisiva batalla frente a realistas y reformistas ${ }^{52}$.

${ }^{48}$ No debemos olvidar que España aún se hallaba en plena guerra con las tropas ocupantes.

49 "Los diputados que componen este Congreso y representan a la Nación española, se declaran legítimamente constituidos en Cortes generales y extraordinarias, y que reside en ellas la soberanía nacional" (Tomado de SÁlZ DE VARANDA, R. Colección de leyes fundamentales. Zaragoza: Acribia, 1957, p. 27). Esa autoproclamación en Asamblea constituyente también se da durante el comienzo del constitucionalismo francés, ya que, una vez convocados los Estados Generales, el 5 de mayo de 1789 se produce la apertura de los mismos en Versalles (ciento setenta y cinco años después de la última convocatoria) y los acontecimientos se desarrollan con enorme rapidez, transformándose los Estados Generales en Asamblea Nacional el 17 de junio, mediante acuerdo del bajo clero y un tercer estado cuyos representantes habían duplicado su número por decisión del propio Monarca a la hora de convocar Estados Generales el 24 de enero de ese año.

50 Las Cortes gaditanas, reunidas por vez primera en la Iglesia de San Pedro, en la Isla de León el 24 de septiembre de 1810, estaban compuestas por 240 diputados que nunca llegarán a reunirse juntos (sólo un centenar acudieron a la jura inicial). Respecto a la obra liberalizante de las Cortes de Cádiz, desde septiembre de 1810 a 1814 vid. ComelLAs(o. c., p. 89), citada también en Fernández SEgAdo (o. c. p. 68, nota 44).

51 Vid. Vera Santos (o. c. p. 34), donde se recuerda, siguiendo a Hamon, Troper y BURDEAU (o. c., pp. 301-302), cómo los mandatos de los representantes que acceden a la reunión de los Estados Generales en 1789 reconocían también el mantenimiento de la Monarquía, eso sí, vinculada a la existencia de una norma escrita que positivizara sus derechos y libertades.

52 En cuanto a la extracción social de los diputados, nos remitimos a indicar la mayor presencia de los no pertenecientes a la nobleza o alto clero. Ideológicamente podemos diferenciar en su seno tres posiciones: los absolutistas, partidarios de una vuelta al régimen anterior; los reformistas, basados en las tradiciones patrias y que también abominan del nuevo espíritu democrático; y los liberales, con Argüelles a la cabeza, tendentes a implantar un régimen que acogiese las nuevas ideas ilustradas. NúÑEz RIVERo y MARTínez SegarRA (o. c., pp. 67-68) diferencian una dicotomía entre liberales o doceañistas, y conservadores reformistas; además, por su origen, destacan a los diputados americanos, que apoyaron la causa liberal. 
Va a ser el día de San José de 1812, cuando se jure la nueva Constitución. Una Constitución cuya azarosa vida ${ }^{53}$ será acorde con su también complicada elaboración. Desde marzo de 1812 y hasta la vuelta de Fernando VII, su vigencia estuvo sometida a los avatares bélicos; una vez se produce la venida del deseado Rey, mediante un Decreto de 4 de mayo de 1814, éste decide derogar la Constitución. Será en 1820, a partir del levantamiento de Riego en Cabezas de San Juan, cuando el Rey apruebe el Decreto de 7 de marzo, aquél que da lugar a un manifiesto regio fechado tres días más tarde, en el que el Monarca hipócritamente indica: "marchemos francamente, y yo el primero, por la senda constitucional; mostrando a la Europa un modelo de sabiduría, orden y perfecta moderación ${ }^{54}$. El denominado Trienio liberal acaba con la ocupación - nuevamente- por parte de Francia de la península con los conocidos como "Cien mil hijos de San Luis» ${ }^{55}$. El Duque de Angulema

53 SÁnchez Agesta (o. c., págs, 121-124) alude a esta cuestión en un epígrafe cuyo título resulta muy sugerente: «Muerte y resurrección. El mito de Cádiz». Incide en cierto carácter taumatúrgico Solís, $\mathrm{R}$ "Cara y Cruz. La primera Constitución Española», en Revista de Estudios Políticos, n. ${ }^{\circ} 126,1962$, pp. 143-156 [146] aludiendo a la concepción de la misma como "panacea de todas las virtudes políticas», en un primer momento. Especialmente incisivo resulta el autor al destacar que, ya en 1823, esa ciudad de Cádiz que en 1812 vibraba de alegría y esperanza liberal, ahora acusa una absoluta falta de fe en la antes milagrosa Constitución y en el "deseado" Rey Fernando VII (o. c., pp. 150-154). Por su parte ComelLAS(o. c., pp. 108-110), vincula el día lluvioso y de viento en que se promulgó, y la realidad del texto gaditano, destacando como, salvo en reducidos círculos liberales, no llegó a ser comprendida por la Nación española. Cita, a estos efectos, tanto periódicos de la época como correspondencia variada. Aún más, indica que, aquellos que llegaron a entenderla, no tuvieron de ella la mejor de las opiniones (de "repugnancia» y "horror", habla el autor).

54 Vid., por ejemplo, sobre los motivos subyacentes al levantamiento de Riego, las opiniones de SUÁREZ y ViCENS ViVES que recoge FERRANDO BAdíA en "Vicisitudes e influencias de la Constitución de 1812», en Revista de Estudios Políticos, n. ${ }^{\circ} 126$, 1962, pp. 169-226 [176-180]: apetencias personales de los jefes militares, el oro americano para comprar voluntades y evitar que el ejército expedicionario español partiera hacia América a sofocar la independencia de las colonias, las sociedades secretas, y quizás, en un pequeño grado, incluso las ideas tendentes al logro de la libertad en el suelo patrio. También muy interesantes sus conclusiones respecto a la influencia de la Constitución gaditana en Europa, sobre todo en Portugal e Italia (pp. 195-203 y 203-216). Sobre la influencia de la Constitución gaditana en el «Risorgimento" italiano, del mismo autor, La Constitución española de 1812 en los comienzos del "Risorgimento", Roma-Madrid: CSIC, 1959. Especialmente relevante el cotejo que realiza FERRANDO BADÍA entre el texto doceañista y la Constitución del reino de las dos Sicilias de 1821 (pp. 142-152).

55 En realidad los franceses que ocuparon España, fueron unos 35.000. La acuñación del término viene de la apertura de las Cortes galas por Luis XVIII, Asam-

(C) UNED. Revista de Derecho Político 
toma Madrid en mayo de 1823 y da paso a la "década ominosa", derogando el texto gaditano, que nuevamente entrará en vigor de manera provisional el 13 de agosto de 1836 después del motín de la Granja, a través de un decreto de la Reina Gobernadora, manteniendo su vigencia hasta la aprobación, en junio de 1837, de la Constitución liberal $^{56}$.

Mucho $-\mathrm{y}$ bien - se ha discutido sobre las influencias recibidas por los constituyentes doceañistas a la hora de elaborar la Constitución ${ }^{57}$.

bleas que oyeron un discurso regio en el que se aludía a cómo "cien mil franceses están preparados para avanzar invocando al Dios de San Luis para conservar en el Trono de España a un nieto de Enrique IV». Y así es como acaba el Trienio liberal, después del Congreso de Verona. Francia, sí, otra vez Francia, bien es cierto que, para variar, con la connivencia de nuestros propios gobernantes. ¡Que buen criado —nos referimos al pueblo español—, si hubiera buen señor!. Vid. igualmente sobre el Congreso de Verona y la intervención de la Santa Alianza que concluye con la in vasión del Duque de Angulema y la vuelta al absolutismo fernandino, FERRANDo BADíA (“Vicisitudes...” o. c., pp. 221-226). El día primero de octubre de 1823, nuevamente Fernando VII volvía a derogar la Constitución de Cádiz. Es de destacar que el paso de Angulema por las tierras de España no encontró mayores problemas, antes bien fueron más los apoyos, tal y como refleja VARELA SUANZES-CARPEgNA (o. c., pp. 68-69).

56 Resumen de acontecimientos respecto al Bienio 1812-1814, el Sexenio absolutista (1814-1820), el Trienio liberal (1820-1823), y al motín de la Granja (1836), por todos, en Torres del Moral (o. c., pp. 48-54), CaVero y Zamora (o. c., pp. 80-84) o NúÑez Rivero y MaRTínez SegarRa (o. c., pp. 87-90).

57 Seguimos en este punto los resúmenes de la discusión doctrinal que encontramos en SÁnchez Agesta (o. c., págs 64-69), Fernández Segado (o. c., pp. 70-74) y TOMÁs VILLARROYA (o. c., pp. 16-18). Interesante artículo el de AYMES, J-R «Le débat ideológico-historiographique autour des origines françaises du liberalisme espagnol: Cortes de Cádiz et Constitution de 1812». En Historia constitucional. Revista electrónica, n. ${ }^{\circ}$ 4, junio 2003. El autor destaca diferentes fases de este debate, si bien une dentro del mismo a autores como Argüelles y Muñoz Torrero y su defensa del carácter patrio del texto gaditano con numerosos libelos y hojas volanderas de la época. Destaca las opiniones, ya en la mitad del siglo XIX, de Quintana y el conde de Toreno, favorables a la españolidad de la Constitución de 1812, o las de Martínez de la Rosa o Modesto Lafuente, con argumentaciones más híbridas, reconociendo así el influjo francés a pesar de ser éste denostado; después de pasar por los finales del XIX y las opiniones de Costa o Picabea, ya en el franquismo destaca el auge revisionista con que el nuevo Estado trata los siglos XVIII y XIX, silenciando o atacando - siguiendo la obra del padre Vélez - la importancia de la aportación liberal de la Constitución gaditana. Muy destacables las opiniones de Diego Sevilla en 1949 o Artola diez años después abogando por una mayor relevancia de las influencias patrias $y$, por ende, las diferencias con el texto galo, dentro de la conjunción entre la españolidad del texto y su carácter revolucionario propio. Ya en democracia se rei- 
Dejando a un lado la también polémica discusión sobre la unión en el texto de elementos tradicionales y liberales ${ }^{58}$, a nuestros efectos, y dentro de estos últimos, debemos hacer hincapié en la mayor o menor influencia de la Constitución francesa de 1791 en el texto de Cádiz. Y es que, tanto en las partes dogmática como orgánica, como también en la concepción liberal de las instituciones, las influencias, como veremos y explicaremos a lo largo de las páginas que siguen, son evidentes. La otra opción es que "la tradición» española hubiera influenciado en la doctrina constitucional de allende los Pirineos, y esta posibilidad se nos presenta improbable.

Las posturas doctrinales respecto a la influencia del texto francés de 1791 en el patrio de 1812, pueden dividirse en tres. En primer término encontramos a quienes consideran que se produce un paralelismo casi perfecto entre ambos textos ${ }^{59}$. De una posición más tenue pero también

vindicó esta Constitución y sus influencias francesas no son criticadas sino destacadas y reconocidas (Solé y Aja, Tierno, Tomás y Valiente o Tuñón de Lara). Vid. también los números monográficos de la Revista de Estudios Políticos (1962) y de la Revista de las Cortes Generales (1987) referidos a la Constitución doceañista.

58 En esta cuestión somos de la opinión de ComELLAS: «No nos engañemos ante las apariencias. La alusión histórica puede ser un medio de cohonestar o de intentar cohonestar, la revolución española frente a la oposición realista y aún frente a la conciencia del país" (o. c., p. 83). Y es que, a pesar de las declamaciones que encontramos, tanto en el Discurso Preliminar («Nada ofrece la Comisión en su proyecto que no se halle consignado del modo más auténtico y solemne en los diferentes de la legislación española»), como en el Preámbulo (al aludir a las "antiguas leyes fundamentales de esta Monarquía" como elementos para promover la gloria, la prosperidad y el bien de la Nación), no podemos olvidar que también en el mencionado Discurso Preliminar se indica: "Pero al mismo tiempo no ha podido menos de adoptar [la Comisión] el método que le pareció más análogo al estado presente de la Nación, en que el adelantamiento de la ciencia del Gobierno ha introducido en Europa un sistema desconocido en los tiempos en que se publicaron los diferentes cuerpos de nuestra legislación, sistema del que ya no es posible prescindir absolutamente, así como no lo hicieron nuestros antiguos legisladores, que aplicaron a sus reinos de otras partes lo que juzgaron útil y provechoso". Valgan las citas meritadas para descubrir lo que parece evidente: la "amalgama" o "mixtura" (SÁNCHEZ AGESTA, o. c, p. 64), de la tradición y los nuevos tiempos, bien que prevalecen los últimos sobre la primera, algo evidente si nos encontramos con la ruptura del régimen absolutista y el advenimiento del liberalismo. Las citas del Discurso Preliminar están tomadas de SeVILLA ANDRES, o. c., pp. 115 y 116.

59 Siguiendo a VÉLEZ, en su obra Apología del Trono, escrita en 1818, en la que cotejó el articulado de ambas Constituciones observando sus identidades. De la misma opinión es SUÁREZ, F. "Sobre las raíces de las reformas de las Cortes de Cádiz», en Revista de Estudios Políticos, 1962, n. ${ }^{\circ} 126$, pp. 31-67. Dejando a un lado cues- 
apostando por dicha influencia se muestra otro de los autores estudia$\operatorname{dos}^{60}$, aludiendo al "in medio virtus" entre la notoria influencia y los elementos que se separan de los constituyentes franceses. Argumentan a favor de la idiosincrasia propia del texto gaditano aquellos que motivan más los elementos que difieren - así el principio de libertad religiosa, la participación del Rey en la potestad legislativa o la reserva de poderes reglamentarios del Monarca en el caso francés-, que los que corren en paralelo ${ }^{61}$.

Como ya hemos indicado más arriba, consideramos por nuestra parte que, sin negar elementos discordantes, las similitudes entre ambos textos, mejor dicho, las influencias del francés sobre el gaditano, son lo suficientemente evidentes para partir de este principio, abogando por dicha influencia. Lo anterior no quita que se admita - como no, en textos separados por diferentes realidades culturales, económicas y políticas, además de por veinte años desde la redacción del primero de ellos hasta la aprobación del segundo-, la existencia de elementos propios que son diferentes en cada caso.

Entrando ya en materia, el texto de 1812 presenta como características formales el tratarse de la Constitución más extensa de nuestro país ${ }^{62}$, además de su rigidez. En cuanto al primero de los condiciona-

tiones que el autor destaca (tales como porqué las Cortes no asumieron la solicitud de uno de sus individuos (Gómez Fernández) respecto a identificar en las leyes patrias los antecedentes de la normativa a aprobar (pp. 34-37), la debilidad de la argumentación de Argüelles sobre la real vinculación del texto gaditano con Las Partidas (39-45), o las alusiones a Villanueva y su estudio normativo en el que encontró ¡diez divergencias! entre los textos español y francés (pp. 45-47)), nos parece especialmente relevante no sólo su apuesta por la real vinculación entre el texto de 1791 y el gaditano, defendiendo las teorías de Vélez (pp. 47-61), sino la advertencia que, sobre la terminología, realiza en las páginas 48 y 49 y en la nota 13 . SUÁREZ intenta destacar así que el uso, más o menos afortunado, de conceptos tales como "traducción literal, afinidad, determinante, copia servil, negar toda originalidad, ser modelada por la francesa", supone destacar, despojándonos de prejuicios, que la influencia entre los textos de 1791 y 1812 existe; y que la misma viene de Francia hacia España es evidente, por cuestiones temporales, además de doctrinales y culturales.

60 Sánchez Agesta (o. c., pp. 64 y ss).

61 Son partidarios de esta posición, y así los cita TomÁs VilLARROYA (o. c., p. 18) Artola o SeVILLa Andrés.

62 Muy expresivo nos resulta Comellas(o. c., pp. 101-102) indicando que "duplica, triplica y aún cuadruplica a las restantes» (...) "los legisladores doceañistas no fiaron nunca la eficacia de su obra a las «interpretaciones» de sus futuros ejecutores; quisieron darlo todo hecho, todo resuelto y explicado de antemano con una me- 
mientos, los trescientos ochenta y cuatro artículos regulan sistemáticamente la organización institucional española ${ }^{63}$ —no así el apartado dogmático, como más adelante veremos-. Este exceso regulador presenta como finalidad la introducción de la mayor seguridad jurídica posible en el advenimiento del régimen constitucional, un régimen opuesto frontalmente al anterior. $Y$ todo ello imbuido de una clara tarea pedagógica, como se recoge en el tan traído y llevado artículo 368, crisol del intento liberal por formar a la sociedad en los principios ilustrados constitucionales ${ }^{64}$. Las consideraciones negativas que se achacan por la doctrina a la amplitud de esta Constitución aluden a sus excesos materiales y a su reglamentismo. Así, no parece adecuado regular en sede constitucional materias cuya formalización, como posteriormente se impondrá, resulta excesiva en esta sede: tal es el caso del sistema electoral. Igualmente el exceso de detallismo en lo regulado, ese reglamentismo, se observa, por ejemplo, en la materia antes citada, así como en otras en las que los preceptos esenciales aparecían desvirtuados al lado de otros cuya insignificancia hacían del texto doceañista una amalgama jurídicamente compleja.

También destaca este texto por su carácter especialmente rígido (Título X. «De la observancia de la Constitución y modo de proceder

ticulosidad rayana en la casuística» (...) "la Constitución de 1812 está elaborada más que ninguna otra, "ordine geométrico", como la "Etica» de Spinoza".

${ }^{63}$ Idéntica calificación de extensa sufre la Constitución francesa de 1791. No ha de argumentarse el porqué: sin tener en cuenta el preámbulo y el Título primero, doscientos siete artículos (algunos de amplia redacción) conforman un texto francés que, obvio es destacarlo, como en el caso español, supone una ruptura del régimen que hace necesaria una formalización positivizada y que la misma se exteriorice.

${ }^{64}$ Recordemos el tenor literal del citado precepto: «El plan general de enseñanza será uniforme en todo el reino, debiendo explicarse la Constitución política de la Monarquía en todas las universidades y establecimientos eclesiásticos, donde se enseñen las ciencias eclesiásticas y políticas". A más abundamiento cabe citar a CoMELLASnuevamente (o. c., p. 102): "También esta preocupación por la claridad esquemática puede entenderse en función de su carácter de "catecismo", destinado a ser aprendido en las escuelas y a ser explicado por el párroco durante la misa mayor". El cumplimiento de este artículo va a ser la causa de la creación de las primeras cátedras de Derecho constitucional en 1813 y 1814, en Valencia y Madrid, debido a impulso de entidades privadas y no a una acción decidida por el poder político, unas cátedras cuya finalidad aparece alejada de la teorética jurídica, constituyéndose en cátedras de formación ciudadana. Como sabemos, su creación fue efímera, toda vez que Fernando VII, el 12 de mayo de 1814, decretó "la vuelta a las cadenas" que el absolutismo representaba (SÁNCHEZ AGESTA, L. "Las primeras cátedras españolas de Derecho constitucional", en Revista de Estudios Políticos, 1962, n. ${ }^{\circ} 126$, pp. 157167 [en especial 157-163]. 
para hacer variaciones en ella", arts. 372 a 384), tal y como ocurre con la Constitución francesa de $1791^{65}$. Así, el artículo 375 expresaba con carácter general la intangibilidad de la misma hasta pasados ocho años "después de haberse puesto en práctica la Constitución en todas sus partes", equívoca redacción que en cualquier caso denota el intento de proceder a estabilizar el régimen constitucional antes de proceder a su reforma ${ }^{66}$.

En cuanto a su naturaleza, se alude al carácter popular de la misma, como ya se observó en la propia redacción del Decreto de septiembre de 1810, y recoge el Preámbulo de la propia Constitución ${ }^{67}$. Pero siendo de origen popular, no podemos hablar de que sea una Constitución impuesta al Monarca, ya que se redacto y aprobó sin su presencia pero no en su contra, sino al revés, para encumbrar al Trono a un Fernando VII ${ }^{68}$ que la traicionará en repetidas ocasiones.

65 La Constitución gala citada no podría reformarse hasta pasados diez años de su aprobación, a pesar de las primeras palabras del artículo 1 del Título VII del propio Texto - que aludía al carácter básicamente libre de cada generación para determinar su propia vida constitucional-, tal y como se desprende del desarrollo del procedimiento a seguir: y es que se deben aprobar los extremos de la reforma durante tres legislaturas consecutivas, dejando luego transcurrir otras dos (arts. 2 y 3 ). En la cuarta de las cinco legislaturas se conforma la Asamblea de revisión constitucional con nuevos miembros, en todo caso diferentes a los que componían la tercera (arts. 5 y 6).

66 El procedimiento establecido para proceder a la posible reforma puede resumirse en cinco aspectos: 1. Propuesta de reforma por escrito, apoyada y firmada por, al menos, veinte diputados; 2 . Triple lectura antes de admitir a discusión la reforma; 3. Examen de la propuesta de reforma por las siguientes Cortes por mayoría de dos tercios; 4. Aprobación definitiva por unas terceras Cortes por idéntica mayoría; 5. Publicación de la reforma y comunicación a las autoridades.

67 «Las Cortes Generales y extraordinarias de la Nación española (...) decretan la siguiente Constitución política para el buen gobierno y recta administración del Estado". Destacan CAVERo y Zamora (o. c., pp. 66-67), citando a SÁNCHEZ AgeSTA el necesario carácter popular del texto, vinculándolo al vacío existente ante la ausencia de los Reyes, el repudio generalizado del Consejo de Castilla por su condescendencia con el invasor, o el desprecio popular hacia la Junta de Gobierno que designó Fernando VII para que dirigiese la Nación en su ausencia.

$68 \mathrm{Y}$ es que el artículo 179 reconoce como Rey a Fernando VII, que «actualmente reina", además de que, en la aprobación de la Constitución, la primera alusión que se realiza es nominalmente al mismo. Algo similar se proclama del texto galo de 1791 ya que, como adujimos, los mandatos de los representantes ante la convocatoria de Estados Generales recogían el mantenimiento de la Monarquía. Sí va a ser un texto impuesto a la Corona a raíz de su entrada en vigor tras los sucesos de 1820 y 1836 (levantamiento de Riego y motín de la Granja). 
Se consideran como principios constitucionales básicos del texto liberal la soberanía nacional, la división de poderes, la representación nacional, el principio de igualdad, el principio de libertad y el de confesionalidad y unidad religiosa ${ }^{69}$.

El artículo 3 indica que "la soberanía reside esencialmente en la Nación, y por lo mismo pertenece a ésta exclusivamente el derecho a establecer sus leyes fundamentales ${ }^{70}$. La situación de prevalencia de la Constitución sobre el anterior derecho divino de los reyes, se observa igualmente en el Preámbulo constitucional y en un artículo 173 que, referido al juramento regio, lo expresa con claridad. Esta lucha entre legitimidades será un elemento que sobrevuele todo el edificio constitucional a lo largo y ancho de su tumultuosa existencia71.

Basado en el anterior, aparece el principio de división de poderes ${ }^{72}$, con la consagración de unas Cortes que, junto al Rey hacen las leyes (art. 15), un Rey que ejecuta las leyes (art. 16) y unos tribunales que las aplican (art. 17) (33 $^{7}$. En el fondo, lo que el principio del Barón de Secondat expresaba no era sino una limitación de las competencias regias, de los poderes reales, dando paso así al concepto de Monarquía limitada en la que el Rey aparecía como un poder constituido más ${ }^{74}$.

69 Seguimos a Fernández Segado (o. c., pp. 80-94) y a TorRes del Moral (o. c., pp. 39-44). Otros autores realizan diferentes clasificaciones aunque sistemáticamente abogamos por las de los Catedráticos complutense y de la UNED por resultarnos más completas.

70 Idéntico sentir aparece en el artículo 3 de la Declaración de Derechos del Hombre y del Ciudadano y artículo 1 del Título I de la Constitución francesa de 1791.

71 Este será el motivo teórico por el que Fernando VII no acata la Constitución en 1814 (4 de mayo), amén del apoyo teórico del conocido como «manifiesto de los persas" (22 de abril).

72 Vid. el texto francés de 1791 a partir del estudio de las funciones interorgánicas. Los artículos 3, 4 y 5, del Título III de dicho texto constituyen el modelo de referencia de nuestros artículos 15 a 17.

73 El Poder judicial es el encargado de aplicar las leyes (arts. 17 y 242). Los jueces son nombrados por el Rey a propuesta del Consejo de Estado (art. 237 y 171.4), frente al sistema de elección popular del texto francés de 1791. Se crea un Supremo Tribunal de Justicia (art. 259) cuyas competencias vienen referidas en el artículo 261.

${ }^{74}$ Sigue pues, en gran medida, el ejemplo francés de 1791 con una separación estricta de poderes. Como veremos más adelante, en ambos textos constitucionales, los miembros del Poder legislativo no pueden ser nombrados ministros por el Rey, gozando de inviolabilidad por sus opiniones; el Rey tampoco podía disolver el Cuerpo Legislativo, por lo que en caso de conflicto, Rey-Legislativo, el ordenamiento no preveía la posible solución al mismo. Quizás sea esta falta de relación interorgánica, además de las inexistentes soluciones en caso de conflicto, la causa de 
En tercer lugar aludimos al nuevo concepto de representación que aparece en el texto gaditano, también siguiendo el caso francés: se rompe con el mandato imperativo propio del régimen estamental y aparece el mandato representativo que hace que el representante lo sea de la Nación y no de sus votantes o representados, pudiendo velar por unos intereses generales que a veces difieren de los intereses de todos. Así el artículo 27 alude a las Cortes como "la reunión de todos los diputados que representan a la Nación", insistiendo en dicha representación nacional un artículo 100 que prejuzga la búsqueda del bien general de la misma por aquellos ${ }^{75}$.

Pero la Constitución de 1812 también encuentra su apoyo en una igualdad que ya se observa en el discurso preliminar que redacta Argüelles ${ }^{76}$ aludiendo a la igualdad ante la ley y la unidad de códigos, principios que se constitucionalizarán en los artículos 248 y $258^{77}$.

Sin olvidar el principio de confesionalidad y de unidad religiosa ${ }^{78}$

que la Constitución de 1791 se aplicase durante menos de un año, ya que las relaciones entre el Rey y la Asamblea se van tensando cada vez más por la ejecución del derecho de veto que denotaba un claro enfrentamiento de posiciones ideológicas encontradas, representadas por la Corona y la asamblea (LAVROFF, D. G. Le Droit Constitutionnel de la Vème République. Paris: Dalloz, 1999, p. 24). Vid. DebBasch, Ch. et Pontier, J-M. Les Constitutions de la France, Paris: Dalloz, 1996, pp. 6-7. De "fracaso" se califica esta separación de poderes tan estricta (PACTET, P. Institutions politiques. Droit constitutionnel. Paris: Masson, 1991, p. 270).

${ }^{75}$ En el artículo 2 del Título III del texto de 1791 podemos leer: «La Nación, la única de quién emanan todos los poderes, sólo los puede ejercer por delegación. La Constitución francesa es representativa: los representantes son el Cuerpo legislativo y el Rey". Nos remitimos, igualmente, al apartado en el que observemos el sistema electoral para la elección de diputados a Cortes, ejemplo de proceso representativo.

76 Vid. Discurso preliminar en SeVILLA ANDRÉs o. c., pp. 115-160. También en ARGÜELLES, A. de. Discurso preliminar a la Constitución de 1812. (Introducción de Luis Sánchez Agesta). Madrid: Centro de Estudios Constitucionales, 1989.

77 Con las excepciones del fuero eclesiástico y el militar (arts. 249 y 250). Vid. ToRRES Del Moral (o. c., p. 43) y su referencia, además, a como, por Decreto de Cortes de 1811, se suprimieron los señoríos con los privilegios que conllevaban.

78 "La religión de la Nación española es y será perpetuamente la católica, apostólica y romana, única verdadera. La Nación la protege por leyes sabias y justas y prohíbe le ejercicio de cualquier otra». Vid. SÁNCHEZ AGESTA (o. c., pp. 113-121) respecto a cuestiones tales como los apasionados debates sobre el tema o los referidos a la Inquisición. Como sabemos, la cuestión religiosa va a ser uno de los temas de mayor protagonismo en el constitucionalismo histórico español. La Declaración décima de la de derechos del hombre y del ciudadano sigue derroteros distintos, ya que permite el ejercicio de diferentes creencias con el límite del orden público. 
que recoge el artículo 12, va a ser el de libertad ${ }^{79}$ el basamento de una serie de derechos que se van a positivizar de manera desordenada en el texto gaditano. $Y$ es que, si bien aparece clara la idea revolucionaria plasmada en la Declaración de derechos del hombre y del ciudadano, el constituyente español no fue capaz de armonizar y ordenar los mismos. No obstante, en el texto de 1812 (además de un artículo 4 que indica que «la Nación está obligada a conservar y proteger por leyes sabias y justas la libertad civil, la propiedad y los demás derechos legítimos de todos los individuos que la componen ${ }^{80}$ ), encontramos los siguientes

79 En cuanto a los derechos reconocidos en la Declaración de Derechos francesa, el paralelismo con el régimen español es evidente, independientemente de la positivización concreta de uno u otro derecho. Se trata de concebir los mismos como límites negativos a la actuación del Poder, en un comienzo del liberalismo que los irá aumentando y perfeccionando en sus garantías. La Declaración de derechos del hombre y del ciudadano entronca con las ideas de la llustración. En palabras de Michelet (Histoire de la Révolution française (en SegnaC: La Révolution de 1789. Paris, 1934 , t.l, p. 162), según cita GarCía PelaYo, o. c., p. 463, nota 8 . No es tampoco ajena a las Declaraciones de Derechos habidas en los nacientes Estados Unidos ni a su Declaración de Independencia. Así, en la Declaración de Independencia de 4 de julio de 1776 podemos leer "Que todos los hombres han sido creados iguales y que han sido dotados por el Creador con ciertos derechos inalienables, entre los cuales están la vida, la libertad y la persecución de la felicidad». El artículo 1 de la Declaración de 1789 expresamente indica que "Los hombres nacen y permanecen libres e iguales en derechos». Este catálogo de derechos suponen sin duda una limitación a la actuación del poder público, a unos órganos que van a encontrarse sometidos al principio de la ley como expresión de la voluntad general que ya expresase Rousseau, tal y como leemos en el artículo 6 y se desarrolla en la parte orgánica de la Constitución de 1791; aparte de la referencia a principios de organización pública -así el artículo 16 con su alusión a las posteriormente denominadas por la doctrina parte orgánica y dogmática de cualquier Constitución, o el artículo 3 en el que se reconoce expresamente la soberanía nacional-, los derechos que se recogen en la Declaración viene referidos a los principios básicos de libertad y de igualdad. Así se recogen, respecto al primero de ellos, la libertad personal, la de pensamiento o la de expresión, junto a la propiedad (arts. 9, 10 o 17), bien que olvida otros derechos que sí verán la luz en el texto constitucional de 1793, tales como la libertad de culto, la libertad de enseñanza, la de reunión o la de asociación. La igualdad se concretiza en el ámbito de contenido legal y de participación de todos en la propia formación de la misma y a optar a cargos públicos (art. 6). En fin, que esta "máquina de guerra» contra el Antiguo Régimen que es la Declaración de Derechos (GODECHOT, J. Les Constituciones de la France depuis 1789. Paris: Gannier Flammarion, 1995, p. 26) va a quedar en el frontis del constitucionalismo francés, como demuestran las referencias a la misma a lo largo del mismo, así como su explícita aplicación en el caso de las Constituciones de la IV y V Repúblicas.

80 Vid. artículos 1, 2 y 17 de la Declaración de derechos del hombre y del ciudadano.

(c) UNED. Revista de Derecho Político

N. ${ }^{\circ} 66-2006$ 
derechos: a) la seguridad personal (art. 287), por la que ningún español podrá ser apresado sin previa información sumaria del hecho y mandamiento judicial que se le notificará en el momento mismo de la detención. El artículo 290 por su parte indicaba la necesidad de presentar al juez a todo arrestado para que declare ante él antes de ingresar en prisión, debiendo ser dictada la prisión por auto motivado (art. 293), permitiéndose el pago de fianzas (art. 295); b) en segundo término, y como derechos del detenido podemos aludir al derecho a conocer la causa de la prisión dentro de las veinticuatro horas siguientes a la misma (art. 300), el derecho a un proceso público (art. 302) y la prohibición de tormento (art. 303); y todo lo anterior aderezado por unas garantías procesales que recogen los artículos 244 y 247 : uniformidad procesal para todos los casos e individuos, además del principio de competencia del Tribunal juzgador, previamente determinado por la ley; c) igualmente destacan otra serie de derechos como la inviolabilidad del do-

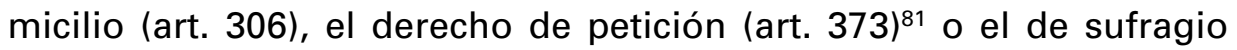
(art. 27), bien que realizado a través de grados, como posteriormente veremos; y d) por último destaca la presencia de un artículo 371 en el que se protege la libertad de expresión ${ }^{82}$. La redacción de este derecho adopta un sistema represivo, alejándose de la censura previa, y aparece regulado en un Título IX dedicado a la instrucción pública, ubicación enormemente significativa para el entendimiento de dicho derecho no sólo como tal sino como elemento esencial para el desenvolvimiento del sistema democrático, para convertirse, en terminología actual, en garantía institucional; un derecho que, por otra parte, ya aparece reconocido por las Cortes gaditanas al aprobar el decreto de libertad política de la imprenta de 10 de noviembre de $1810^{83}$.

81 Vid. igualmente las Disposiciones generales de la Constitución de 1791.

82 Si exceptuamos, "ex" artículo 12, la referida a la cuestión religiosa. La Declaración de derechos de 1789 , así como las Disposiciones generales del texto de 1791 también garantizan la libertad de expresión.

83 Aboga por una triple significación de este derecho, según se deduce del Discurso Preliminar a la Constitución SÁNCHEZ AGESTA (o. c., pp. 108-113): contribución directa a la ilustración y adelantamiento general de las Naciones; alimenta la independencia y libertad de la Nación y de los españoles, además de conformar un verdadero régimen basado en la opinión pública. Muy expresivo de la importancia del reconocimiento de este derecho nos resulta FERNÁNDEZ SEgADO (o. c., pp. 90-92). 


\subsection{Organización institucional}

La parte orgánica -trufada de ese espíritu rousseauniano ${ }^{84}$ que se denota en la redacción de los artículos 6 (obligación de los españoles de ser justos y benéficos) y 13 (el fin de cualquiera sociedad política es el bienestar de los individuos que la componen)-, supone el exponente máximo del intento de limitar los poderes regios y establecer un sistema de frenos y contrapesos que posibilitara un sistema liberal en España, constatación máxima de la aplicación del concepto antes citado de soberanía nacional, tal y como lo formulase Sieyès.

\subsubsection{El Poder legislativo}

Van a ser las Cortes («reunión de todos los diputados que representan la Nación, nombrados por los ciudadanos", según leemos en el artículo 27), el órgano que aparece regulado constitucionalmente en primer lugar, lo que pone de manifiesto su estudiada prevalencia sobre el Monarca. Aparecen así unas Cortes monocamerales en lo organizativo, elegidas por sufragio indirecto de cuatro grados, dotadas de autonomía frente al Rey y con funciones de orden legislativo, económico financiero, de administración y fomento y de orden político y constitucional ${ }^{85}$.

En esta etapa se esgrimirán una serie de argumentos, tanto a favor como en contra de las segundas Cámaras, que a lo largo del siglo XIX se continuarán utilizando intelectual y fácticamente, adecuándose a las nuevas circunstancias y con resultados muy distintos, ya que el bicameralismo ${ }^{86}$ será la estructuración más utilizada para la construcción

${ }^{84}$ Sobre la ideología revolucionaria y la influencia de Rousseau, vid. SÁNCHEZ AgESTA (o. c., pp. 70-79).

${ }^{85}$ Seguimos así a Tomás Villarroya (o. c., pp. 18-22).

${ }^{86}$ Argumentos a favor del bicameralismo son los expresados por Jovellanos en sus obras. Se basa el autor en Obras publicadas e inéditas de D. Gaspar Melchor de Jovellanos. Madrid: BAE, 1951, citada en BERTELSEN, o. c. pp. 25 y ss. Los argumentos aludidos son los siguientes: A. Puesto que históricamente los nobles y los clérigos forman parte integrante de las Cortes, Jovellanos considera que no era el momento más adecuado para modificar esa costumbre e introducir en España un "sistema democrático inoportuno". Si además se descarta el unicameralismo por no servir como elemento de contención del pueblo y del poder del Monarca, y la división del legislativo en tres cámaras resulta excesiva, la única opción que se puede aplicar es la bicameral. B. La Segunda Cámara se constituye como cuerpo intermedio capaz de corregir las posibles desviaciones de poder tanto del Monarca como de una asamblea popular ya que, si se instaurase de nuevo el despotismo o se produjese la ve- 
del edificio legislativo español ${ }^{87}$. Al final se adoptó un monocameralismo representativo de los intereses nacionales ${ }^{88}$.

nida de un asamblearismo del tipo francés, los estamentos privilegiados, ocupantes de asientos en el Senado, serían los primeros en considerarse desprotegidos, viendo conculcada su posición prevalente. C. Además el bicameralismo presenta ciertas ventajas para la actividad legislativa. $Y$ esto a un doble nivel: en cuanto a la formación de la ley se considera, a la luz de lo ocurrido en la Francia revolucionaria, que la actuación de dos cuerpos deliberantes producirían "leyes prudentes y saludables"; igualmente, a la hora de la sanción real, el Monarca se verá compelido a realizarla al ser las dos Cámaras las que han decidido mostrar su apoyo a dicho proyecto legislativo. D. Se alega, en cuarto lugar, el ejemplo foráneo, remitiéndose tanto a Gran Bretaña como a Estados Unidos. E. También influye Jovellanos en el intento de adopción del bicameralismo, motivándolo coyunturalmente en un claro argumento de prudencia política ya que, de un lado, todos los estamentos están luchando contra los franceses y, de otro, si no se sigue dicha representación estamental, se podría caer en un sistema democrático que "no sólo todo buen español sino todo hombre de bien, debe mirar con horror".

87 Siguiendo a SÁnchez Agesta, Fernández Segado considera la polémica entre el monocameralismo y la existencia de dos Cámaras como un aspecto esencial para la comprensión del constitucionalismo histórico español. Así, por ejemplo, se observa en las discusiones en los periodos constituyentes de 1837 y en la "non nata" de 1856. (FERNÁNDEZ SEGADO (o. c., p. 52). Sobre esta importante cuestión vid., a mayor abundamiento, Vera SANTOS, J. M. Senado territorial y presencia de notables. Madrid: Senado, 1996, pp. 36-40.

${ }^{88}$ Los argumentos que se manejan dialécticamente son: A. No se admiten las Cortes bicamerales estamentales por ser "costumbre de incierto origen y no sujeta a regla alguna", refutándose así el principio histórico. Igualmente se consideran innecesarias porque ya no existen privilegios de clase y la distribución de la nobleza en nuestro país es bastante confusa, hecho éste que alteraría un buen sistema de elecciones (ARGÜELLES, o. c., pp. 82-83). B. La representación estamental bicameral no es positiva pues conlleva una lucha por los propios intereses, olvidando así los intereses generales. En el Discurso preliminar, Argüelles argumenta lo siguiente: «Pero, Señor, la razón más poderosa (...) es que los brazos (...) provocarían la más espantosa desunión, fomentaría los intereses de los cuerpos, excitaría celos y rivalidades (...). Tales, Señor, fueron las principales razones por que la Comisión ha llamado a los españoles a representar a la Nación sin distinción de clases ni estados. Los nobles y los eclesiásticos de todas las jerarquías pueden ser elegidos en igualdad de derecho con todos los ciudadanos; pero en el hecho serán siempre preferidos. Los primeros por el influjo que en toda sociedad tienen los honores, las distinciones y la riqueza; y los segundos porque a estas circunstancias unen la santidad y sabiduría tan propias de su ministerio" (Ibídem, p. 84). C. El ejemplo británico no es válido por lo expuesto en los apartados A y B. Es decir, la negación de los privilegios de clase y el carácter negativo de la representación estamental que tiende a confundir el interés "de todos» con el interés general que preconizase Rousseau. D. Aunque no se explicitase, también pesó en la decisión final de adoptar un sistema 
En cuanto al sistema electoral para la elección de los diputados, cuyo número venía dado por los artículos 31 a 33 (esto es, un diputado por cada setenta mil almas, con carácter general), en los artículos 34 a 104 observamos un sistema de sufragio indirecto de cuatro grados: los vecinos de cada municipio elegían compromisarios en relación con su población; posteriormente éstos nombraban un elector de parroquia; en tercer lugar los electores de parroquia se reunían en la cabeza de partido y nombraban un elector de partido; la unión de éstos en un colegio provincial constituiría el órgano encargado de elegir los diputados a Cortes por cada provincia ${ }^{89}$. El artículo 92 expresaba que, para poder resultar elegido diputado, era necesario tener una renta anual procedente de bienes propios, intentando así que el poder legislativo quedase en manos de la burguesía ${ }^{90}$.

En tercer lugar aludíamos a la autonomía organizativa y funcional de las Cortes. La vida de la Cámara se realizaba a espaldas del Monarca y de sus ministros, lo que supone un régimen de absoluta separación de poderes. Cada año (art. 104), el primero de marzo, de manera automática y sin intervención regia, se produce la autoconvocatoria de las Cortes, durando tres meses consecutivos ${ }^{91}$ (art. 106). Tampoco podía

monocameral, anular la posibilidad de que la Cámara Alta pudiese servir de freno a las aspiraciones burguesas. Así lo considera la mayor parte de los autores (entre otros TORRES DEL MORAL o. c., p. 44). Los ya citados argumentos en defensa y también en contra del bicameralismo aparecen a la hora de la discusión del artículo 27 del proyecto en las sesiones celebradas los días 12 y 13 de septiembre de 1811. La Asamblea legislativa francesa es igualmente unicameral (art. 1, Cap. I, T. III), a pesar de que el proyecto comenzó partiendo del bicameralismo.

89 Según los datos que indica Tomás VILLARROYA (o. c., pp. 19-20), los electores primarios serían unos tres millones, que nombraban doscientos mil compromisarios, dieciséis mil electores parroquiales y unos cuatrocientos sesenta electores de partido.

${ }^{90}$ El sufragio indirecto de doble grado del texto de 1791 partía de los ciudadanos activos, que eran los que participan en las asambleas departamentales. Debían ser éstos ciudadanos franceses, varones, mayores de veinticinco años y pagar un censo similar a tres días de trabajo por cuenta ajena. El resto de los ciudadanos se conocen como "pasivos", pues gozan de los derechos reconocidos en la Declaración pero no participan en los asuntos públicos Como ya indicamos, y siguiendo a LAVROFF (o. c., p. 24), de un total de veinticuatro millones de franceses, serían ciudadanos activos en torno a cuatro millones y medio. Los ciudadanos activos participan a nivel departamental y a continuación, en un segundo estadio, un uno por ciento constituyen la asamblea electoral, siendo elegibles un total aproximado de cuarenta mil personas que han de pagar un censo que va de cien a cuatrocientos jornales de trabajo.

${ }^{91}$ Estos tres meses podrán incrementarse en otro mes más si lo solicitase el Rey o las propias Cortes lo aprobasen por dos tercios de votos (art. 107). En el caso fran- 
el Monarca disolverlas ${ }^{92}$ (no se aprecia esta potestad en ningún artículo constitucional), nombrándose una Diputación Permanente de siete miembros que dotaba de permanencia a las Cortes, destacando por sus funciones de vigilancia constitucional y legal, convocar Cortes extraordinarias, e intervenir en nombramiento y suplencias de los miembros de la Cámara (art. 160). Estas Cortes gozaban de autonomía organizativa y reglamentaria (art. 127) ${ }^{93}$, dotando a sus diputados de inviolabilidad por sus opiniones políticas (art. 128), al igual que ocurre en el texto galo ${ }^{94}$. Así mismo se establecía la incompatibilidad entre los cargos de Secretario de Despacho y Diputado (art. 95) ${ }^{95}$, no pudiendo aquéllos acudir a las Cortes, salvo que presentaran una iniciativa en nombre del Rey, debiendo acudir del modo y manera que las Cortes determinen, prohibiéndose en cualquier caso que se vote en su presencia (art. 125).

Por otra parte, el mandato presentaba una duración de dos años (art. 108) ${ }^{96}$, en un claro intento de permitir el acceso al cargo público al mayor número de ciudadanos y potenciar también la independencia de los representantes. No podían resultar reelegido sino por otra diputación (art. 110).

Por último debemos referirnos a las funciones de las Cortes; unas funciones específicas que servían en última instancia como freno a posibles injerencias del Monarca. Así el artículo 131 enumeraba veintiséis facultades, que vamos a agrupar por materias ${ }^{97}$. En primer término hemos de aludir a la potestad legislativa (art. 131, $1^{\circ}$ ) mediante la que la Cámara puede "proponer y decretar las leyes, e interpretarlas y derogarlas en caso necesario». La iniciativa legislativa pertenece a cada

cés (art. 1, Cap. I, T. III) esta Cámara es permanente, hecho éste que aumentaba aún más su autonomía. En España, la identidad propia de las Cortes se apuntala con la existencia de la Diputación Permanente (arts. 157-160).

92 El artículo 5, Cap. I, T. III de la Constitución de 1791 impide expresamente la disolución regia.

93 Vid. art. 4, Cap. III, T. III, del texto francés.

94 Artículo 7, Sec. V, Cap. I, T. III, Constitución 1791.

${ }_{95}$ El art. 2, Sec. IV, Cap. II, T. III del texto francés así lo prescribe.

96 Idéntica temporalidad presenta el artículo 2, del Capítulo primero, del Título III de la Constitución francesa de 1791.

97 Seguimos, como dijimos, a Tomas Villaroya (o. c., p. 21). Este autor destaca que estas Cortes, imbuidas del espíritu revolucionario liberal, se inmiscuirán en otras tareas no propias de su ámbito competencial, conculcando letra y espíritu de la Constitución por ellas aprobada. Este sistema de listas concretas es el que observamos también en el modelo francés; más concretamente en los artículos 1 a 5 , de la Sección primera, del Capítulo III, del Título III. 
diputado (art. 132), compartiendo la misma con el Monarca (art. 171) quién participa también en el proceso legislativo en última instancia a través de la sanción en un plazo de treinta días (art. 142), entendiéndose que si no hubiera pronunciamiento al respecto, se consideraría sancionada la ley (art. 145). El Rey igualmente disfrutaba de la posibilidad de vetar las normas a él sometidas a sanción durante un periodo de tres lecturas y aprobaciones consecutivas anuales; si éstas se produjesen, el Rey quedaba obligado a sancionar (art. $149^{99}$.

Estas Cortes, amén de la función principal antes expuesta, gozaban de funciones de orden político y constitucional. Así recibían el juramento del Rey, nombraban la Regencia del reino, vigilaban por la observancia de la Constitución y procedían a su reforma. En el ámbito económico y financiero, fijaban los gastos de la Administración, establecían anualmente las contribuciones o establecían aduanas; en lo tocante a administración y fomento, establecían el plan general de enseñanza, promovían y fomentaban todo tipo de industria, y aprobaban los reglamentos sanitarios y de policía del reino ${ }^{100}$.

Entre las funciones de estas Cortes gaditanas encontramos un esbozo de control del Ejecutivo. Como expresa el apartado vigésimo quinto del artículo 131, las Cortes pueden «hacer efectiva la responsabilidad de los Secretarios de Despacho y demás empleados públi$\cos { }^{101}$.

98 Esta iniciativa legislativa regia puede calificarse como indirecta. $Y$ es que, el Monarca puede proceder a proponer una norma (art. 131, decimocuarta), pero lo realiza a través de los Secretarios de Despacho, quiénes, por el artículo 125, asisten a las sesiones de modo y tiempo que indiquen las Cortes y nunca están presenten en las votaciones. Podría darse el caso de que las Cortes no tomasen en consideración la iniciativa regia, por lo que nos encontramos ante una iniciativa de segundo grado o indirecta, potenciándose así el peso de las Cortes y de los diputados. Idéntica degradación competencial del Rey en cuanto a la iniciativa legislativa encontramos en el art. 1, Sec. I, Cap. III, T. III de la Constitución de 1791, precepto en el que, después de incluir como poderes y funciones del Cuerpo legislativo la propuesta y decreto de las leyes, indica que "el Rey sólo podrá invitar al Cuerpo legislativo a que tome un asunto en consideración".

99 Del sistema francés ya dijimos que el Monarca también goza de un derecho de veto suspensivo ante los proyectos que presente el Legislativo, en un plazo de dos meses, bien que si dos legislaturas siguen manteniendo el proyecto, el Rey se encuentra obligado a sancionarlo (arts. 1 a 7, Sec. III, Cap. III, T. III).

100 Vid. Ios artículos 1 a 5, de la Sección primera del Capítulo III, del Título III del texto francés de 1791, donde encontramos un sistema de listas similar.

101 Con Fernández Segado (o. c., pp. 101-102) convenimos que es un control seudo-criminal y en ningún caso político, teniendo en cuenta los artículos 228 y 229. 


\subsubsection{El Poder ejecutivo}

El Título IV del texto de 1812 viene referido al Rey, un Rey que lo es no sólo por la gracia de Dios, sino por la propia Constitución ${ }^{102}$, como podemos leer en el Preámbulo de la misma. Y es que si el Rey es sagrado e inviolable (art. 168) ${ }^{103}$, la justa reciprocidad hace que el artículo 225 indique que esa responsabilidad recaiga en los Secretarios de Despacho, quienes firman las órdenes regias responsabilizándose de las mismas ante las Cortes ${ }^{104}$. Dejando a un lado las normas sucesorias y otros aspectos tales como la Regencia, debemos entrar en el estudio de las facultades reales dentro de este sistema de poderes y contrapoderes, en este primer momento del liberalismo español. Diferenciaremos así sus actuaciones en relación con el poder legislativo y ejecutivo, aludiendo a las limitaciones que la propia Constitución indica ${ }^{105}$.

Según establece el artículo 15, la potestad legislativa residía en las Cortes con el Rey. Esta concurrencia regia en el proceso normativo debemos concretarla en los aspectos antes citados: iniciativa legislativa, sanción y promulgación ${ }^{106}$. En materia ejecutiva encontramos potestades reglamentarias (expedición de decretos o reglamentos de ejecución

Destacar que no nos hallamos ante la existencia de un ejecutivo colegiado, si bien a partir de la experiencia del Trienio liberal y su ratificación por decreto de Fernando VII, podemos aludir a la existencia de lo que se conocerá como Consejo de Ministros. Este modelo de responsabilidad, aunque no política, lo encontramos igualmente en los artículos 4 a 6, de la Sección IV, del Capítulo III, del Título III del texto de 1791. Respecto a la responsabilidad gubernamental en la Constitución de 1812, la influencia en la misma del texto galo de 1791 y el claro matiz penal de ésta, vid. GonzÁlez HeRnández, E. La responsabilidad penal del Gobierno. Madrid: Centro de Estudios Políticos y Constitucionales, 2002, pp. 119-125.

${ }_{102}$ Como ya expusimos, el constituyente gaditano en ningún caso optó por ir en contra de la Monarquía. Más, siendo cierto lo anterior, también lo es que corrían vientos liberalizadores y la venida del constitucionalismo conllevaría la paulatina sustitución del poder absoluto del Rey. En palabras de FernÁndez Almagro, que recoge TORRES Del MORAL (o. c., p. 46) "los legisladores de Cádiz no pensaron ni por un momento en romper con Fernando VII. Pero ni por un momento tampoco pensaron que éste volviese como se fue».

${ }^{103}$ Como también indica respecto al Rey francés el texto de 1791 (art. 2, Sec. I, Cap. II, T. III).

${ }_{104}$ Arts. 4 y 5 de la Sección IV, Cap. II, T. III.

105 Así sistematizaremos los artículos 170 a 172 de la Constitución de Cádiz, siguiendo en esta ocasión a Merino Merchán (o. c., pp. 54-55).

106 Nos remitimos a lo ya expuesto. Consideramos más adecuado el desarrollo de estas cuestiones al analizar las Cortes y no referidas al Poder ejecutivo, debido a la importancia crucial del órgano legislativo en este momento histórico. 
de las leyes), político-administrativas (administración de justicia, nombramiento de magistrados, concesión de honores, derecho de gracia, nombramiento libre de los Secretarios de Despacho), militares y exteriores (mando de los ejércitos, nombramiento de generales, disposición de la fuerza armada, nombramiento de embajadores, dirección de la política exterior), y económico-financieras (acuñar moneda y decretar las inversiones) ${ }^{107}$.

Pero mucho más llamativa que este elenco competencial, amplio pero tasado, se nos antoja las restricciones expresas que la Constitución de Cádiz recoge en su artículo 172 referidas al Monarca, restricciones insólitas hasta la llegada del constitucionalismo liberal. Así, y en el orden político, el Rey no puede impedir que se celebren Cortes, ni proceder a su disolución ni suspensión ${ }^{108}$; no puede ausentarse del reino sin su consentimiento ${ }^{109}$, ni ceder o enajenar parte alguna del territorio o bienes nacionales ${ }^{110}$; en cuanto a su actividad en materia de relaciones exteriores no cabe la posibilidad de que el Monarca realice alianzas ofensivas ni tratado especial de comercio con ninguna potencia sin consentimiento de las Cortes ${ }^{111}$; tampoco puede imponer directamente contribuciones ${ }^{112}$ ni turbar la propiedad de sus bienes a ningún particular, debiendo igualmente solicitar a las Cortes consentimiento para proceder a su matrimonio ${ }^{113}$.

Dentro del mismo Título dedicado al Rey aparecen regulados los Secretarios de Estado y de Despacho (capítulo VI, arts. 222-230), unos

107 Potestades que encontramos en el artículo 171. Recordemos que la potestad ejecutiva pertenece también al Monarca francés "ex" art. 4, T. III, siendo desarroIladas tales competencias en los artículos 1 a 4 del Capítulo IV, del Título III, en un claro ejemplo de reserva material que lo separa del caso español.

108 Arts. 1 y 5 del Capítulo I del Título III, del texto galo de 1791.

109 El artículo 7 de la Sección I, Capítulo II del Título III indica que el Rey francés debe regresar al reino en el plazo que le indique el Cuerpo legislativo, plazo que no puede ser superior a dos meses. En caso contrario, se entiende que abdica.

110 Entre las competencias exclusivas pertenecientes al Cuerpo legislativo, la Constitución francesa de 1791 indica que figura la de dictar normas sobre la administración y ordenación de la enajenación de bienes nacionales (art. 1, Sec. I, Cap. III, T. III).

111 Art. 3, Sec. I, Cap. III, T. III, en relación con el artículo 3 de la Sección III de la Constitución de 1791.

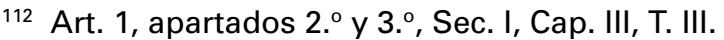

113 Estas restricciones, sistematizadas y expresas, son sorprendentes. Pero no debemos dejar de destacar que no resultan ser los más relevantes límites a la actuación regia, a sus antes omnímodos poderes. Como es lógico, el reparto competencial general al que aludimos en este trabajo, es el marco genérico y de mayor alcance que la relación del artículo 172. 
Secretarios cuyas funciones consistían, como ya hemos indicado, en ejercer la potestad ejecutiva en nombre del Rey asumiendo la responsabilidad con la firma de las mismas (art. 225), respondiendo ante las Cortes (art. 226) ${ }^{114}$. Las siete Secretarías que indicaba el artículo 222 podían variarse según lo exigieran las circunstancias, siendo el Rey quien libremente nombraba y cesaba a los mismos (art. 171). Para poder ser nombrado Secretario de Despacho únicamente se requería la ciudadanía española (art. 223). Con anterioridad, ya hemos hablado del sistema de control jurídico estatuido en torno al artículo 225, y allí nos remitimos.

El Consejo de Estado es la siguiente institución regulada, también dentro del Título referido al Rey (Capítulo VII, arts. 231-241). Aparece como único consejo del Rey (art. 236). Está compuesto por cuarenta miembros (art. 231): cuatro Grandes de España, cuatro eclesiásticos -al menos dos de ellos obispos - y el resto personas de señalados servicios o conocimientos. Al menos doce consejeros deben ser nacidos en las provincias de Ultramar, siendo incompatible el cargo con ser diputado (art. 232). Son nombrados y elegidos por el Rey (art. 233) si bien en la elección participan unas Cortes que deben presentar una lista triple para cada uno de los individuos y sectores (art. 234). Los artículos 236 y 237 expresan las funciones de este órgano: emitir dictamen al Rey en los asuntos graves de gobierno, sobre todo previamente a sancionar o no las leyes, declarar la guerra y hacer tratados. Es igualmente el órgano que propone las ternas al Rey con los candidatos a ocupar beneficios eclesiásticos y plazas de judicatura.

\section{EL ESTATUTO REAL DE 10 DE ABRIL DE 1834}

\subsection{Introducción. Parte dogmática}

La muerte de Fernando VII, ocurrida el 29 de septiembre de 1833, abre un enfrentamiento bélico entre carlistas - partidarios de una Monarquía absolutista tradicional ${ }^{115}$ _, e isabelinos, quiénes pretendían

114 Cf. Arts. 1 a 8 de la Sec. IV, Cap. II, T. III. En el caso francés la responsabilidad de los ministros se dirime ante el Rey, aparte de la responsabilidad penal en la que, en determinados casos tasados, pueden incurrir.

115 Interesante la proclama del general carlista Maroto en Estella (17 de marzo de 1839): "Voluntarios, pueblos del reino de Navarra y provincias vascongadas: viva el Rey, viva la subordinación. Sea nuestro lema: religión o muerte, y restauración de nuestras antiguas leyes, por cuyos principios moriremos todos" (NÚÑEZ RIVERO Y 
una evolución de ésta hacia parámetros liberales. Por tanto, la problemática derivada de la cuestión sucesoria no se refiere tanto a personas como a modos de entender la realidad política ${ }^{116}$.

Martínez Segarra o. c., pp. 92 y 93). Vid. Cavero y Zamora (o. c., pp. 89-96) respecto al problema sucesorio, la aprobación del Estatuto Real y la realidad política creada a la muerte de Fernando VII.

116 La propia situación política, las tensiones existentes en este momento histórico, se dejan sentir en los diferentes proyectos de reforma institucional que se intentan vean la luz mientras se aprueba o rige el Estatuto Real. Aparte de la denominada Tabla de Derechos de agosto de 1834 a la que posteriormente haremos mención, destacan los proyectos de reforma de la sociedad isabelina y el Ministerio Istúriz.

Después de señalar otras circunstancias que explican la presencia de la influencia del doceañismo en la época del Estatuto Real -así el proyecto de respuesta al discurso de la Reina Gobernadora con razón de la apertura de Cortes en julio de 1834, la Tabla de Derechos de agosto de dicho año, o la discusión en septiembre de la deuda contraída por la Monarquía, diferenciando si la misma provenía del Trienio liberal o del absolutismo fernandino-, TOMÁs VILLAROYA destaca la existencia de una "conspiración isabelina" (pp. 255-256) que, alternativamente quería alcanzar dos fines: la sustitución del texto del Estatuto Real, antes de que se abrieran las primeras Cortes, por "un proyecto de ley fundamental o reforma del Estatuto»; si esto no se produjese, se solicitaría en la sesión de apertura de Cortes, con la colaboración de los diputados afiliados a la sociedad, que "el Estamento popular se declarase en Cortes presuntas y que estas Cortes, con los poderes necesarios de las provincias examinasen la Constitución de 1812 para que en ellas hiciesen las reformas que el tiempo y la experiencia hubieran acreditado ser necesarias en aquella ley". Son palabras literales tomadas por el autor citado de AVINARETA, impulsor de aquella conjura. Vid. TomÁs VillarRoYA, J. "La Constitución de 1812 en la época del Estatuto Real», en Revista de Estudios Políticos, 1962, n. ${ }^{\circ}$ 126, pp. 251-276 [252-256]. Como veremos a lo largo de este estudio, se trataba de dar un importante paso en la parlamentarización de la Monarquía y en la separación de competencias entre las propias de un Jefe de Estado y las de Jefe de Gobierno, rompiendo así con el sistema del Estatuto Real. Este proyecto fue presentado a la Reina Gobernadora en julio de 1834, mediante una exposición firmada por Flórez Estrada, acompañada del texto redactado por Juan Olavarria, quien estaba muy estrechamente relacionado con liberales belgas. Así lo podemos leer en SeVILLA ANDRÉs, o. c., p. 277, citando a PIRALA.

Con las Cortes disueltas en 1836, el Ministerio Istúriz intentó presentar el día 25 de mayo un Proyecto de revisión del Estatuto Real. No consiguió su objetivo ya que el 21 de mayo de 1836 aparece el voto de censura contra Istúriz como una moción de no confianza que firman sesenta y ocho procuradores. Ante este hecho, el día siguiente la Regente disolvía las Cortes. Aparece así la necesidad de obtener la confianza de las Cámaras, dándose paso al inicio de una práctica claramente parlamentarista, si bien existía ya el precedente de la solicitud de confianza de Mendizábal el día 31 de diciembre de 1835. Cita NoHLEN a Rico y Amat para destacar la literalidad de la primera moción de censura que hubo en España, bien que sin ningún efecto jurídico, ya que la decisión del cambio de gobierno pertenecía a la Reina 
Con el nombramiento de María Cristina como Reina Gobernadora, y tras la publicación del Manifiesto neoabsolutista de Cea Bermúdez, éste se ve obligado a abandonar el cargo de Presidente del Consejo de Ministros, siendo sustituido por Martínez de la Rosa (15 de enero de 1834), quién comienza con rapidez a elaborar (en sede gubernamental, puesto que las Cortes no se hallaban convocadas) un texto constitucional que formaliza y presenta a la real sanción el 10 de abril de 1834.

Este Estatuto Real presenta una naturaleza jurídica muy discutida ${ }^{117}$ que puede resumirse en que, si bien formalmente es una convocatoria de Cortes con rasgos externos de Carta otorgada, realmente se trata de una Constitución pactada con motivo del desacuerdo de los sectores isabelinos liberales con el Manifiesto de Cea ${ }^{118}$. Sí existe acuerdo a la

Regente: «Rogamos al Estamento que declare que las personas que forman el Gobierno en este momento no merecen la confianza de la nación" (NOHLEN, D. "Ideas sobre gobierno parlamentario y práctica constitucional en la España de la época del Estatuto Real", en Revista de Estudios Políticos, 1968, n. ${ }^{\circ} 162$, pp. 93-119 [107, nota 63]). ARTOLA, M. (Partidos y programas políticos. 1808-1936. Los partidos políticos, vol. I, Madrid, Alianza, 1991, pp. 45-47 indica cómo tanto en el caso de Mendizábal como en el de Istúriz la desconfianza parlamentaria surge ante disputas por la consecución o no de una más alta representación electoral. Vid. textos de los proyectos de la sociedad isabelina y del gabinete de Istúriz, en SEVILLA ANDRÉs, o. c., vol. I, pp. 277-281 y 291-295.

117 Vid. Fernández Segado (o. c., pp. 128-129) o Clavero (o. c. pp. 49-50). En resumen, y siguiendo a los autores citados, Merino Merchan (o. c., pp. 65-66) indica las siguientes teorías: a) es una norma funcional similar a las leyes constitucionales francesas de la III República (Torres del Moral); b) se trata de una Carta otorgada por la Corona al pueblo (Fernández Segado, Solé Tura); c) de Constitución pactada la califica Fraile; d) Posada ya indicó en 1935 que se trataba de un Decreto de convocatoria de Cortes, teoría que defienden también Sánchez Agesta y Sevilla Andrés; e) el Estatuto supone una vuelta a las Leyes Fundamentales del Reino, tal y como expusieran sus propios autores, Javier de Burgos y Martínez de la Rosa entre ellos. Cita en conclusión el autor a Tomás y Valiente, destacando así el carácter ecléctico del texto: por su origen, es una Carta otorgada; por su temática, una Ley de Cortes; por su apariencia, es una norma que restaura las Leyes Fundamentales del Reino y por su contenido ideológico es el símbolo del moderantismo español en su versión más conservadora y menos liberal.

118 FrAILE CLIVILLES, o. C., págs 243-244. De cualquier manera la cuestión como hemos visto, no es pacífica. La opinión de Fraile, parece más adecuada no sólo a la dicción literal del artículo 1 del Estatuto Real sino también a la «Exposición del Consejo de Ministros a S.M. la Reina Gobernadora" que acompaña al texto del Estatuto Real, donde se observa la motivación de la convocatoria de Cortes con el fin de restaurar esta institución y dotar de mayor legitimidad a Isabel II frente a las pretensiones dinásticas de los carlistas. (SeVILLA ANDRÉs, o. c., pp. 257-270). En concreto (pp. 259-260), podemos advertir como «la reunión de las Cortes del Reino es el único me- 
hora de caracterizarlo como breve (50 artículos divididos en cinco títulos), flexible ${ }^{119}$, incompleto (no aparece referencia alguna a la parte dogmática ${ }^{120}$, separándose con ello del ejemplo francés de la Carta

dio legal, reconocido, sancionado por la costumbre inmemorial en semejantes casos [litigios dinásticos], para acallar pretensiones injustas, quitar armas a los partidos y pronunciar un fallo irrevocable que sirva de prenda y de fianza a la paz futura del Estado". VARELA SUANZES-CARPEgna (o. c., pp. 69-70) destaca cómo se aboga por un nuevo texto para que los "cristinos" lograsen mayor apoyo, nacional e internacional, frente a los que pudiera obtener el pretendiente D. Carlos.

119 De la redacción del propio artículo 30 y de la realidad de la época así se desprende. Con Tomás VILLARROYA (o. c., p. 34) podemos indicar que, mediante sendas exposiciones que elevaron a la Reina Gobernadora los Ministerios Mendizábal e Istúriz (en septiembre de 1835 y mayo de 1836), se podía leer "la necesidad, generalmente reconocida, de celebrar una reunión de las Cortes del Reino, de acuerdo con la autoridad del Cetro, para revisar el Estatuto Real», o que habría de procederse, previa convocatoria de Cortes generales «a la revisión del Estatuto Real de acuerdo con la autoridad del Trono". Idéntico carácter flexible presentan los textos galos de 1814 y 1830.

120 Por esa razón surgió la petición de un grupo de Procuradores liberales para dotar al Estatuto Real de la parte orgánica de la que carecía. Es el proyecto, que no cuajó, conocido como "Tabla de Derechos", fechado en agosto de 1834. Después de un importante preámbulo, se propone la consignación de una serie de derechos, articulados en doce preceptos, entre los que destacan: la libertad individual (art. 1); la de imprenta, prohibiendo la censura previa (art. 2); la seguridad personal, junto a la prohibición de detención irregular (art. 3); la inviolabilidad del domicilio (art. 5); la igualdad e irretroactividad de la ley (arts. 4 y 6); la igualdad de acceso a cargos y empleos públicos (art. 7); la igualdad tributaria, de manera proporcional a los haberes (art. 8); la inviolabilidad de la propiedad, permitiéndose su cesión al Estado previa indemnización (art. 9), o la responsabilidad de funcionarios y Secretarios de Despacho si conculcan, entre otros, los derechos de propiedad, libertad y seguridad personal (arts. 10 y 11). Vid. dicho proyecto en el Diario de Sesiones del Estamento de Procuradores, de 28 de agosto de 1834, pp. 94-96. También en SEVILLA ANDRÉs (o. c., pp. 283-289). En el texto de la sociedad isabelina igualmente observamos una serie de derechos como la libertad, la seguridad personal, el acceso en igualdad a los cargos o el derecho de propiedad, reconociendo la utilidad pública o la libertad de expresión e imprenta sin censura previa. A éstos debemos añadir otros que aparecen dispersos por el texto como el derecho de petición a las Cortes (art. 10) o las resultantes de la aplicación de la igualdad económica (art. 59). De igual manera, en el proyecto de reforma presentado por el gabinete Istúriz se reconocen una serie de derechos en sus artículos 1 a 7, destacando la igualdad de acceso cargos (art. 2), la libertad de imprenta sin censura previa (art. 3), el derecho de petición individual a las Cortes o al Rey (art. 4), la seguridad personal (art. 5) o el derecho de propiedad, bien que cabe su cesión al Estado previa indemnización (art. 6). La inexistencia de carta de derechos, junto al origen del Estatuto Real, alejado de la voluntad popular, son los dos motivos principales por los que los progresistas nunca perdonarán al mismo (VARela SuAnzes-CARPEgna, o. c., pp. 72-73). En cuanto a la Carta francesa 
otorgada de $1814^{121}$, texto que será su principal influencia en otros aspectos, como veremos) y expresión de un moderantismo que posteriormente irá reapareciendo a lo largo de nuestro constitucionalismo.

La soberanía compartida ${ }^{122}$ y la colaboración entre los poderes son los principios básicos caracterizadores de este Estatuto Real. En cuanto al primero de ellos, en ningún artículo se preconiza el sujeto de la soberanía, dándose por supuesto, de manera tácita, que la misma va ser compartida por el Rey y las Cortes, como denota el carácter flexible del texto constitucional ${ }^{123}$. Como lógico colofón del principio anterior se observa una colaboración entre los diferentes poderes; y es que si la Corona y las Cortes comparten la soberanía ${ }^{124}$, aplicando la máxima jurídica "quien puede lo más, puede lo menos", la aportación conjunta de ambas va a ser necesaria en la cotidianeidad política: el derecho de di-

de 1814, efectivamente, se produce un reconocimiento de derechos y libertades fundamentales en la primera docena de artículos de la Carta. La libertad (física —art. 4-, religiosa - art. 5-, o de prensa -art. 8-), la igualdad de todos los franceses (art. 1) o la garantía del derecho de propiedad (arts. 9 y 10), se ven así reconocidos expresamente, bien que, por contra, el gobierno restablece la nobleza (art. 71), hace del catolicismo la religión oficial (arts. 6 y 7), y limita tanto la libertad de prensa - a través de una regulación reglamentaria necesaria para el desarrollo y aplicación de los derechos-, que, en realidad, las pretendidas proclamas generales de igualdad y de libertad, devienen ciertamente limitadas en la práctica. Los mismos son entendidos como concesión regia, nunca como derechos naturales: valga como ejemplo la literalidad del preámbulo a la propia Carta, que comienza aludiendo a "la divina Providencia" como base última de la autoridad regia. Finaliza dicho preámbulo con una solemnidad propia de la gracia del Rey al conceder la Carta: "Voluntariamente y por el libre ejercicio de nuestra autoridad regia, acordamos conceder y otorgar...". La Carta de 1830 reproduce en Francia casi literalmente el elenco de derechos enunciados en el texto de 1814.

121 Sobre la Carta francesa de 1814 vid. Vera Santos (Las Constituciones ..., o. c., pp. 294-299).

122 TorRes del Moral (o. c., p. 59) discrepa de la mayoría doctrinal al considerar que el Estatuto Real se entiende mucho mejor -en su proceso de elaboración, promulgación y contenidos-, desde el concepto de la soberanía regia, ya que el Monarca sólo va a ceder competencias de segundo orden a las Cámaras. El principio de soberanía nacional, junto a la declaración de un elenco de derechos serán las causas esenciales por las que los liberales volverán sus ojos a la Constitución de 1812 observando a ésta como "prenda de legitimidad y de libertad» (TOMÁs VILLARROYA, J. "La Constitución de 1812..." o. c., pp. 251 y 267-270)

123 Es el comienzo en España de la teoría de la "Constitución interna" que utilizará Canovas en el régimen de la Restauración.

124 Principio que se observa más en el texto francés de 1830 -en cuyo preámbulo se observa su carácter pactado, ya que es el propio pueblo francés quién llama al Trono al Monarca-, que en el de 1814. 
solución regia (arts. 24 y 40) o la compatibilidad entre los cargos de ministro y miembro de las Cámaras (no se declara la incompatibilidad entre los mismos) ${ }^{125}$, amén del sistema bicameral, son ejemplos claros de que en el Estatuto Real encontramos el comienzo de unas prácticas y la implantación de instituciones parlamentarias en España ${ }^{126}$.

125 Sobre la discusión respecto a la compatibilidad de ambos cargos, las diferencias teóricas y sus consecuencias prácticas entre el pensamiento de Stuart Mill (prevalencia del Parlamento) y Pacheco (que no llega a proclamarla, utilizando así una postura doctrinaria) vid. NoHLEN, o. c., págs 99-104. Por otro lado, los artículos 54 y 46 de la Carta de 1814 y 1830 indican expresamente que los ministros pueden pertenecer a la Cámara de los Pares o de los Diputados, compatibilidad que, ya en clave interna, ninguno de los proyectos patrios que se presentan como alternativa al Estatuto Real, intentan modificar. Al contrario, los artículos 43 del proyecto de la sociedad isabelina y 41 del propio de Istúriz lo expresan de manera literal.

126 Respecto al texto francés de 1814, debemos recordar que, después del derrocamiento de Napoleón en abril de 1814, es Ilamado al trono Luis Estanislao Javier, quién sería proclamado Rey en cuanto aceptase la propia Constitución. Pero éste, en la declaración de Saint-Ouen ( 2 de mayo), rechaza el ofrecimiento, por considerar que no se recoge el principio legitimista regio en el texto que se le propone sancionar, manifestando su deseo de redactar otro en el que se conjuguen la legitimidad de la Monarquía y los derechos y libertades revolucionarios, siendo éstos concedidos graciosamente por el Rey. A partir de este texto y de su puesta en práctica, se introducirá el régimen parlamentario en Francia, parlamentarismo que será desarrollado por la Carta de 1830. Vid., sobre la Carta de 1830, VERA SANTOS Las Constituciones... o. c., pp. 299-301). Como sintetizan Barthélemy y Duez (BARTHÉLEMY, J. et DuEZ, P. Traité élémentaire de Droit constitutionnel. Paris. 1933, p. 176, citado en García Pelayo [o. c., p. 480]) en este periodo se desarrolla en Francia el gobierno parlamentario, caracterizado por las siguientes notas: a) El Rey elige sus ministros de entre la mayoría del Parlamento, y el Gabinete se retira cuando no encuentra sostén en la misma; b) El gobierno hace frecuente uso del derecho de disolución parlamentaria; c) El Rey despliega un papel activo siguiendo la postura de Guizot (un trono no es un sillón vacío) frente a la de Thiers (el Rey reina pero no gobierna); d) Aparece la interpelación como el más genuino modo de control por el legislativo de las tareas gubernamentales "Es una Constitución reaccionaria que instituye una Monarquía limitada", destacan DebBasch, Ch, Pontier, J.-M., Bourdon, J et RicCl, J. Cl. Droit Constitutionnel et institutions politiques. Paris: Economica, 1990, p. 439), aludiendo así al origen y al modelo constitucional y funcionamiento que disecciona en las páginas 441-444. GUILLENCHMIDT, M. DE Histoire Constitutionnelle de la France depuis 1789. Paris: Economica, 2000, p. 47, citando a CHEVALIER incide más en el desarrollo real que en el régimen expresado en la Carta. Un argumento éste último muy similar al que defiende NOHLEN, diferenciando en el artículo citado entre el régimen institucional establecido y su desarrollo en la práctica.

En cuanto al caso español, citamos a ViLLaRRoYa (o. c., p. 35): «El texto del Estatuto y los Reglamentos de los Estamentos reconocieron formalmente la existencia del Consejo de Ministros, la compatibilidad del cargo de Ministro y la condición de 


\subsection{Organización institucional}

\subsubsection{El Poder ejecutivo}

Ya se ha dicho que el Estatuto Real no contenía alusión alguna a la parte dogmática ${ }^{127}$ y respecto a la parte orgánica sólo dedicaba expresamente su articulado a la regulación de las Cortes. No obstante su Título $\mathrm{V}$ (Disposiciones generales), prevé que el Rey siga teniendo una posición hegemónica, compartiendo en ocasiones el ejercicio de sus

parlamentario, el concurso obligado del Rey y las Cortes a los fines señalados en los artículos 30 y 34 (...) y por último la facultad del Rey de convocar, suspender o disolver las Cortes. Por su parte, la doctrina política de la época afirmó la necesidad de que el Gobierno, para conseguir y conservar el poder, contase con la confianza de las Cortes: por ese camino, durante la época del Estatuto, se planteó, por primera vez en España, la cuestión de Gabinete que permite a éste comprobar la existencia de aquella confianza; y se admitió ya de manera regular y definitiva, el voto de censura que permite al Parlamento ratificar o retirar la confianza inicialmente concedida. Con todo ello, quedó completada la fisonomía del régimen parlamentario que el Estatuto quiso dibujar". VARELA SuANZES-CARPEgna (o. c., pp. 70-72) destaca la importancia de la introducción del sistema parlamentario en el Estatuto Real, junto a otras consideraciones: la concreción y brevedad (que lo alejan de planteamientos iusracionalistas jacobinos), la aparición del bicameralismo y el cambio del sufragio indirecto por el directo censitario. Como más adelante indicamos, NOHLEN (o. c., pp. $93,95,96$ y 97) se opone a la calificación de "gobierno parlamentario" al resultante del Estatuto Real, si bien destaca cómo en la práctica política de la época aparecen ciertos elementos parlamentaristas (responsabilidad política de los ministros, compatibilidad del cargo con el de parlamentario). Cita a Martínez de la Rosa refiriéndose a la compatibilidad de ambos cargos: "La teoría de Cádiz y la doctrina constitucional de 1812 están desacreditadas para con todo el mundo en la absurda oposición que establecieron entre el destino de diputado del país y el de consejero responsable de la Corona", una compatibilidad que se asume siguiendo los modelos británico y francés que aprenden los liberales españoles que son exiliados por Fernando VII en la "década ominosa".

127 Como hemos indicado antes, la inexistencia de parte dogmática será uno de los elementos que hará a la Constitución de 1812 referente esencial del liberalismo de la época del Estatuto Real. Vid. Tomás VILLARRoYA ("La Constitución de 1812...» o. c., pp. 270-274) al respecto de la problemática de los derechos individuales en general, en la prensa de la época y en las Cortes del Estatuto Real, además de con posterioridad. No olvida el autor que, toda vez que entra nuevamente en vigor la Constitución de 1812, después del motín de la Granja en verano de 1836, aquéllos que lucharon por su aplicación comienzan a revisarla dando paso a la Constitución de 1837. Y es que la Constitución de 1812, al pasar de la teoría —casi taumatúrgica, modelo para la oposición al texto del Estatuto Real- hasta la terca realidad, pierde esa caracterización referencial, haciendo buena la máxima aquella de que «Dios castiga a los hombres concediéndoles sus deseos". 
poderes legislativos con las Cámaras. El Rey sigue siendo la figura eje del sistema; la falta de regulación sistemática de sus poderes, junto a la asunción de las competencias por la Reina Gobernadora, amén de la necesidad de que los actos del Monarca deben ser refrendados por un ministro que es responsable hacen, cada vez más, que éste lo sea no sólo ante el Monarca sino ante las Cortes ${ }^{128}$.

Diferenciamos entre las competencias del Monarca en relación con las Cortes y su potestad ejecutiva. Respecto de las primeras, debemos indicar que: a) el Rey gozaba de la facultad exclusiva de convocar las Cortes (art. 24) ${ }^{129}$, separándose del régimen doceañista de autoconvocatoria. Bien es cierto que esta prerrogativa regia venía limitada por la necesidad de convocatoria para tratar asuntos graves o los impuestos (arts. 30 y 35), debiendo ser convocadas en caso de disolución de las mismas en el plazo de un año (art. 44); b) de los artículos 24 y 40 del Estatuto se deriva que el Rey puede disolver las Cortes, para que el pueblo decidiese en caso de conflicto entre la representación nacional y los ministros ${ }^{130}$. c) El Rey igualmente gozaba de iniciativa legislativa exclusiva (art. 31) ${ }^{131}$, pudiendo sólo las Cortes elevar peticiones en ese sentido al Monarca (art. 32) ${ }^{132}$; d) el artículo 33 establecía el derecho de

128 Vid., en idéntico sentido, los artículos 54 y 55 de la Carta francesa de 1814 y 46-47 de la Carta de 1830. En similar orientación, vid. arts. 42 y 40 de los textos de la sociedad isabelina e Istúriz.

${ }^{129}$ Igualmente son convocadas por el Rey en el caso francés de la Carta de 1814 (art. 50). Literalmente reproduce este precepto el artículo 42 de la Carta francesa de 1830.

${ }^{130}$ La disolución sólo afecta al Estamento de Procuradores, debido al carácter vitalicio de los Próceres, si bien las potestades de éstos quedan en suspenso (arts. 42, 43 y 46). Como es sabido este derecho de disolución fue utilizado por la Reina Gobernadora en enero y mayo de 1836 con los gabinetes de Mendizábal e Istúriz; el primero por un pronunciamiento contrario a sus tesis electorales por parte del Estamento de Procuradores; el segundo tras el voto de censura de dicho Estamento. También es competencia del Rey la disolución en los textos franceses de 1814 (art. 50 , bien que debe convocar en tres meses), y 1830 (art. 42). Por su parte, el artículo 38 del texto de la sociedad isabelina indica que el Rey puede disolver el Estamento de Procuradores pero debe convocarle en 90 días. En el caso del proyecto del Ministerio Istúriz, el Rey convoca y suspende las Cortes y disuelve el Estamento de Diputados; en este último caso debe llamar a nuevas elecciones en 6 meses (art. 30).

131 Vid. idéntico régimen en el artículo 16 de la Carta de 1814. En 1830, sin embargo, la iniciativa legislativa será compartida entre el Rey y las Cámaras (art. 15), lo mismo que sucede en los casos de los proyectos de de la sociedad isabelina (art. 4) e Istúriz (art. 12).

${ }^{132}$ El artículo 19 de la Carta de 1814 también permitía que las Cámaras suplicasen al Rey el inicio de la iniciativa legislativa. 
veto del Monarca, siendo éste absoluto y no suspensivo como en el caso de $1812^{133}$.

En cuanto a los poderes ejecutivos del Monarca, los mismos no se especifican en el Estatuto Real pero siempre se entendió por la doctrina y la práctica que gozaba de los clásicos (poder reglamentario, dirección de la política militar, conservar el orden público, designar empleos civiles) $^{134}$. El Consejo de Ministros aparece constitucionalizado (por vez primera en España), junto a la figura de su Presidente, y sus miembros debían refrendar los actos del Monarca (arts. 26, 37 o 40 del Estatuto Real), siendo responsables de los mismos ${ }^{135}$. Esta constatación de rango constitucional referida al órgano colegiado y a su Presidente es la primera vez que se produce en España, cuestión ésta muy importante que traerá como consecuencia la responsabilidad no ya penal sino política. Igualmente, al aparecer la figura del Presidente del Consejo de Ministros, se institucionaliza la misma, entendiéndose que debe ser nombrado por el Rey, si bien también dependería de la confianza de las Cámaras, dentro de un régimen precursor de procedimientos e instituciones parlamentaristas como el que instituye el Estatuto Real ${ }^{136}$.

133 En este caso se separa claramente del veto suspensivo regio que recorren los artículos 21 y 22 de la Carta de 1814. TORRES DEL MORAL (o. c., p. 60), discrepa del carácter absoluto del veto del Monarca "ex» artículo 33 del Estatuto Real, toda vez que realiza una interpretación sistemática del mismo con los artículos 31 y 32, deduciendo que si es el Rey el único órgano dotado de iniciativa legislativa, parecería contradictorio que su veto fuese absoluto, actuando sobre su propia iniciativa. Los artículos 17 y 18 de la Carta francesa de 1830 siguen el modelo del texto de 1814. En los proyectos de la sociedad isabelina (art. 12) e Istúriz (art 31) adoptan el veto suspensivo y el absoluto.

${ }^{134}$ La Carta francesa de 1814 nos presentaba a un Rey, inviolable y sagrado, penal y políticamente irresponsable, dice el artículo 13 que disfruta en exclusividad del poder ejecutivo: declara la guerra, concluye los tratados, tiene la potestad reglamentaria (art. 14).

135 Vid. artículo 13 de la Carta francesa de 1814 y 12 de la fechada en 1830. Sobre la responsabilidad penal de los ministros vid. los artículos 33, 55 y 56 de la Carta de 1814 y el artículo 47 de la de 1830, bien que éste último sigue un sistema similar al norteamericano de acusación por la Cámara Baja y de juicio por la Cámara Alta, sistema que encontraremos asumido en el Reglamento del Estamento de los Próceres y Procuradores del Reino (art. 139) como más adelante veremos, al igual que en los textos de la sociedad isabelina (arts. 24, 25 y 35) y del Ministerio Istúriz (art. 20). Vid. GoNZÁlez HERNÁNDEZ (o. c. pp. 126-127), autora que destaca "el confusionismo" existente en esta época respecto a la responsabilidad penal de los ministros, dependiendo la misma del ámbito más o menos amplio de la responsabilidad política.

${ }^{136}$ «El Gobierno sabe muy bien que el sistema actual es un sistema de mayorías (parlamentarias) ...", indica Martínez de la Rosa, según cita Nohlen (o. c., p. 99). 


\subsubsection{El Poder legislativo}

En cuanto al poder legislativo, cuyas sesiones eran públicas (art. $48)^{137}$, se adopta un sistema bicameral perfecto ${ }^{138}$ sobre la base de unos argumentos ya conocidos y que en su mayor parte aparecen en la

Una vez reflejada la "teoría», destaca este autor, en las páginas 105 a 108, que los nombramientos como Presidentes del Consejo de Ministros del propio Martínez de la Rosa (nombrado por la Regente antes incluso de la promulgación del Estatuto Real), del Conde de Toreno (en contra de la mayoría del Parlamento), de Álvarez Mendizábal y de Istúriz, no fueron sino decisiones libérrimas de la Reina Regente, independientemente de las mayorías parlamentarias que, en el caso de Álvarez Mendizábal, sí apostaron a su favor, lo que no impidió que María Cristina lo destituyera y nombrase a Istúriz. En palabras de NoHLEN (o. c., p. 108) «durante la época del Estatuto Real no se llegó a un cambio de Gobierno que pudiera designarse como parlamentario". Aunque empíricamente así se demuestra, el autor citado no deja de destacar que "algunas características y supuestos del gobierno parlamentario se cumplieron en la práctica más bien casualmente que por obligación", aludiendo, por ejemplo, a que los cuatro Jefes de Gobierno eran miembros del Estamento de Procuradores, así como la mayoría de los ministros; o a la aparición de la primera moción de censura contra el Gabinete Istúriz, si bien, concluye literalmente NOHLEN «el elemento decisivo en el proceso de formación y destitución de los Gobiernos fue la voluntad de la Regente» (o. c., pp. 108-109), por lo que "de un Gobierno realmente parlamentario como sistema político del Estatuto no puede hablarse. A las ideas progresistas sobre el gobierno parlamentario no correspondía la realidad constitucional de aquellos años", ya que "un sistema de gobierno tiene que examinarse -si queremos efectuar una tipología adecuada- más en sus principios estructurales que en sus procedimientos" (o. c., pp. 110-111).

137 Publicidad que se va a recoger en el artículo 27 de la Carta de 1830. En la Carta de 1814, los artículos 32 y 44 declaran secretas las sesiones de la Cámara de los Pares y públicas las de la Cámara de Diputados, bien que sobra con que cinco de sus miembros lo soliciten para que la sesión sea secreta. En el proyecto presentado por la sociedad isabelina (art. 8), las sesiones de los Estamentos son públicas, salvo que lo pidan cinco de sus miembros. El texto de Istúriz (art. 14) también aboga por la publicidad, matizando que serán secretas las sesione si lo pide el Gobierno o un número determinado de miembros de las Cámaras, en cuantía que indicaran sus propios Reglamentos.

138 Vid. por ejemplo, los artículos 24, 42, 43 o 46, preceptos en los que se observa esa identidad competencial entre ambas Cámaras. Como bicameralismo perfecto también se catalogan los textos franceses de 1814 y 1830. También, en España, los proyectos constitucionales supracitados. Apartadas sean las competencias judiciales, en el texto de la sociedad isabelina sólo se observa la diferencia de que las leyes de impuestos y de reemplazos del Ejércitos deben ser votadas primero en el Estamento de Procuradores (art. 28); de igual manera, el artículo 12 del proyecto de Istúriz sigue idéntica prioridad para el Estamento de Diputados respecto a las leyes sobre contribuciones. 
Exposición preliminar ${ }^{139}$ al texto del Estatuto Real. Bicameralismo que se observa en la existencia de dos Cámaras que son denominadas Estamento de Próceres y de Procuradores ${ }^{140}$.

Observando las diferentes categorías establecidas en el Estatuto Real para el acceso a la condición de prócer (arts. 3 a 12) ${ }^{141}$, parece más

139 Vid. SeVILLA ANDRÉs (o. c., vol. l, p. 263 y ss). Encontramos el argumento histórico, el del cuerpo intermedio, el de cuerpo conservador que representa distintos intereses o el basado en el derecho comparado. Cf. a estos efectos lo explicitado en la nota XXXX. Destacar que nos encontramos ante el comienzo de la organización institucional del poder legislativo de forma bicameral.

140 «Me gusta todo lo que lleve el sello de la nacionalidad, me gusta que se llamen Estamentos y no Cámaras; me gusta que se llamen próceres y no pares; me gusta que se llamen procuradores a Cortes y no diputados" (MARTínEZ DE LA ROSA, Diario de Sesiones de la Cámara de Procuradores, 1835-1836, p. 398). TORRES DEL MoRAL califica de "rancias" unas denominaciones (o. c., p.61) que CAVERO y ZAMORA (o. c., p. 100) definen como tradicionales.

${ }^{141}$ El Estamento de Próceres del Reino, a cuya regulación atiende el Título II de esta Norma Constitucional (arts. 3 a 12), quedaba compuesto por individuos pertenecientes a las siguientes categorías: Muy reverendos Arzobispos y reverendos Obispos (art. 3.1.); Grandes de España (art. 3.2); Títulos de Castilla (art. 3.3); «un número indeterminado de españoles, elevados en dignidad e ilustres por sus servicios en las varias carreras y que sean o hayan sido Secretarios de Despacho, Procuradores del Reino, Consejeros de Estado, Embajadores o Ministros Plenipotenciarios, Generales de Mar o Tierra o Ministros de los Tribunales Supremos» (art. 3.4); el artículo tercero en su párrafo quinto prescribe que también podrán formar parte de dicha Cámara "los propietarios territoriales o dueños de fábricas, manufacturas o establecimientos mercantiles que reúnan a su mérito personal y a sus circunstancias relevantes, el poseer una renta anual de sesenta mil reales y el haber sido anteriormente procuradores del Reino"; concluye el artículo tercero aludiendo a una sexta categoría en la cual se encuentran "los que en la enseñanza pública o cultivando las ciencias o las letras, hayan adquirido gran renombre y celebridad, con tal que disfruten una renta anual de sesenta mil reales, ya provenga de bienes propios ya de sueldo cobrado del Erario". SeVILLA ANDrÉs, D. Historia política de España. 1800-1975. Madrid: Editora Nacional, 1974, p. 133, destaca como, junto a la primera categoría -Obispos y Arzobispos-, se puede llegar a alcanzar, por esta vía del artículo 3.4, la categoría de Prócer sin cumplir ningún tipo de requisitos económicos. Igualmente ocurrirá en el Proyecto Istúriz (art.17), aunque en este caso ni siquiera existen categorías. En el modelo francés de 1814 la Cámara de los Pares es mucho más simple: además de los miembros de la Familia Real y los príncipes de sangre, los demás pares son nombrados por el Rey de manera vitalicia o hereditaria, en número indeterminado (arts. 27 y 30). De similar manera se regula en la Carta de 1830 (arts. 23 a 26), siendo idéntico modelo que el del texto de Istúriz (art. 17). Los miembros de la Alta Cámara en el texto de la sociedad isabelina, eran elegidos por el Rey de entre ternas presentadas por las diputaciones provinciales (art. 19) separándose así de los ejemplos anteriormente destacados. 
apropiada la calificación de esta Cámara como aristocrática y no como nobiliaria, a la vista sobre todo de las categorías cuarta (altos cargos a los que no se les exige renta), quinta (propietarios) y sexta (hombres de ciencia). ${ }^{142}$ Tampoco se puede afirmar que sea una Cámara estamental, como parece deducirse de su denominación, ya que se permite la presencia en ella a categorías que, como es el caso de la sexta, rompen con dicha idea.

El artículo séptimo preceptúa que, salvo los Grandes de España que son miembros natos y transmiten hereditariamente su dignidad, los demás próceres serán elegidos y nombrados por el Rey, ostentando el cargo de manera vitalicia salvo sentencia firme que imponga pena infamatoria (art.10). No obstante esta condición vitalicia, y con el fin de permitir un mayor influjo del Monarca, el artículo noveno establece que el número de próceres es ilimitado ${ }^{143}$.

Para ser elegido miembro del Estamento de Procuradores, aparte de tener una edad de treinta años, se pedía estar en posesión de una renta propia anual de doce mil reales y el nacimiento, residencia de al menos dos años o posesión de algún predio en la provincia que le nombre (art. 14.4 del Estatuto Real). Se encontraban sujetos a mandato imperativo (art. 16) de tres años de duración (art. 17) ${ }^{144}$.

El Estatuto no concretaba en su articulado el sistema electoral, ya que el artículo 13 se limitaba a mencionar una futura normativa. Esa aconsejable desconstitucionalización del sistema electoral es la causa por la que, bajo la vigencia del Estatuto Real, se aprobaron dos Decretos electorales (de 20 de mayo de 1834 y 24 de mayo de 1836) ${ }^{145}$; el pri-

142 Así Tomás de Villarroya o. c., p. 42. En contra se muestra Solé Tura y Aja (o. c. p. 29), abogando por un carácter aristocrático.

${ }_{143}$ Tal y como se expresa en la «Exposición del Consejo de Ministros..." antes citada, "con el fin de restablecer el equilibrio entre los varios poderes del Estado", si ello fuese necesario (SEVILLA ANDRÉS o. c., pp. 263-264). Idéntico sentir se recoge en los textos franceses de 1814 y 1830 (arts. 27 y 23, respectivamente), y en el proyecto de Istúriz (art. 17); nuevamente el texto de la sociedad isabelina se separa de los anteriores en una línea más liberal, abogando por un Estamento de Próceres compuesto por un miembro cada cien mil almas (art. 21).

${ }^{144}$ En los textos franceses de 1814 y 1830, el mandato es de cinco años (arts. 37 y 31). Un mandato de cinco años que también, para los miembros del Estamento de Procuradores, reconoce el texto de la sociedad isabelina, bajando a tres años el mandato del Estamento de Diputados que preconizaba el Ministerio Istúriz (art. 24).

145 Seguimos nuevamente a TOMÁs VILLARROYA, uno de los autores que más y mejor han estudiado es régimen del Estatuto Real (vid. Breve historia... pp. 43-44 y El sistema político del Estatuto Real (1834-1836). Madrid: Instituto de Estudios Políticos, 1968, pp. 427 y ss.) 
mero de ellos establecía un sistema de sufragio indirecto de dos grados, siendo electores los españoles varones que tuvieran determinadas rentas, eligiendo compromisarios que, a su vez, designaban a los Procuradores $^{146}$. Un sistema éste que ofrecía notorios inconvenientes: cuerpo electoral muy limitado, de composición excesivamente conservadora al ser censitario ${ }^{147}$. El segundo de los decretos electorales citados ofrecía como características principales, la introducción de la elección directa, eso sí dentro de un sistema también censitario pero abierto no sólo a las grandes fortunas sino a quienes poseyeran determinados títulos académicos o profesionales, abundando así en la parte más liberal de la sociedad ${ }^{148}$.

${ }^{146}$ Los números demuestran lo injusto del sistema: sólo 16.026 electores (0’15\% de la población), podían nombrar a 950 compromisarios.

147 En la Francia de 1814, el sistema se basa en un sufragio censitario (art. 40), mediante el que gozan de sufragio activo los mayores de 30 años y que paguen trescientos francos de contribución directa, pudiendo ser elegibles los varones, mayores de 40 años y que pagasen más de mil francos de contribución (art. 38). Los diputados son elegidos para un mandato de cinco años, renovándose anualmente por quintas partes (art. 37). El peso económico en materia de sufragio se incrementó con la ley de 29 de junio de 1820, conocida como la ley del doble voto, norma por la que se restablecen dos tipos de colegios: los de distrito y los departamentales. Los primeros nombran doscientos cincuenta y ocho diputados y designan de entre los mayores contribuyentes del departamento una lista de electores que, reunidos en colegio departamental, designan ciento setenta y dos diputados. Así los mayores contribuyentes tenían un doble derecho de voto, de tal forma que se calcula que los veinticinco mil propietarios mas acaudalados nombraban el cuarenta por ciento de la Cámara de Diputados. Además se introdujo la modificación normativa de que los datos de contribución que permitían la función de sufragio serían obtenidos una vez realizadas las posibles desgravaciones, por lo que la cuantía se convertía en neta, incrementándose así los requisitos económicos. La legislación electoral en este periodo fue fluctuante, con diferentes normas entre 1814 y 1824: ordenanzas de julio y septiembre de 1815 y 1816 y leyes de febrero de 1817 , junio de 1820 y junio de 1824. En ellas se modificaron cuestiones tales como la duración del mandato parlamentario o el procedimiento electoral (MORABITO, o. c., pp. 185-187). Y todo ello, sin duda, vinculado al intento de control por el Monarca de la posible oposición parlamentaria. En la Carta de 1830 disminuye la edad para disfrutar de sufragio activo a 25 años (art. 34) y a 30 años para ser elegible (art. 32).

${ }_{148}$ El cuerpo electoral quedó integrado por 60.067 personas. Ya sabemos que en julio de 1836 se produjeron los sucesos de La Granja, por los que se proclamó la vigencia de la Constitución de Cádiz. De cualquier manera, en ese mes, el día 13, se celebraron elecciones siguiendo el decreto citado y en las mismas se observan elementos que luego quedarían por costumbre: presentación ante el electorado de los candidatos, exposición en la prensa de su programa electoral o el intento de creación de las primeras asociaciones electorales, germen de los partidos políticos (Fernández Segado, o. c., pp. 135-136 y VilLaRRoya (o. c., pp. 43-44)). 
Sistematizando las funciones de las Cortes, y sabiendo del bicameralismo perfecto existente, podemos decir que las mismas — siendo escasas y en cualquier caso siempre intervenidas por el Monarca-, se pueden dividir entre las propias del legislativo, las atribuciones políticoconstitucionales, las de orden judicial y las económicas. En cuanto a las primeras, debemos decir que ninguna de las Cámaras tenía iniciativa legislativa ya que, como hemos dicho, la misma pertenecía en exclusiva al Monarca (art. 31), bien que las Cámaras pueden ejercer un derecho de petición al Rey para que éste inicie el proceso. Pero siendo esto cierto, los Reglamentos de ambas Cámaras y la propia vida política posibilitaron las enmiendas "in voce» y las escritas en Comisión. Aparte de esto, las propias deliberaciones y el carácter público de las mismas, dotaron a las Cámaras de un importante papel participativo en la legislación.

Como atribuciones político-constitucionales encontramos a unas Cámaras que son las receptoras del juramento del sucesor a la Corona (art. 27) o que pueden recibir consulta y evacuarla a petición del Rey respecto a asuntos graves (art. 30).

En el ámbito judicial, si bien las atribuciones judiciales de la Cámara de los Próceres no venían recogidas en el Estatuto Real, el Reglamento del Estamento de los Próceres y Procuradores del Reino de 1834 (art. 139), establecía que era competente para juzgar a los Secretarios de Despacho, previa acusación a cargo del Estamento de Procuradores; también era competente respecto a los delitos cometidos contra la inviolabilidad del Trono o la seguridad del Estado. Así mismo conocía de los casos por delitos comunes o específicos en que el autor fuese prócer o de la comisión de atentados contra sus propias personas.

Como atribuciones económico-presupuestarias (arts. 34 a 36), en su seno se discutían las Memorias o exposiciones previas a los Presupuestos, así como éstos mismos. Y, encontrándonos en un sistema de doble confianza, no podemos olvidar la importancia política de estas discusiones: es en esta época cuando las discusiones sobre Presupuestos comienzan a alcanzar la importancia política que merecen.

\section{CONCLUSIÓN}

A la vista de los datos expuestos y de las argumentaciones que hemos seguido, alejados de apasionamientos propios de otros tiempos pasados, parece elemental abogar por una evidente influencia del cons- 
titucionalismo francés en los textos españoles que hemos estudiado. Entrando únicamente a constatar las semejanzas de principios, institucionales y normativas, podemos establecer que:

- El Estatuto de Bayona, texto claramente influenciado por Napoleón, supuso el inicio de las ideas constitucionalistas en España, ya que las mismas provenían, como en casi el resto de Europa, de una Francia ilustrada, revolucionaria, liberal, bien que tamizada por el autoritarismo del Emperador francés y devaluada por su desembarco militar forzoso en una España todavía muy ligada al Antiguo Régimen. Así, por ejemplo, la consideración de la Monarquía como órgano esencial y la fragmentación del resto de las instituciones para que perdiesen todo su posible peso político, o la institucionalización de una Monarquía de la familia Bonaparte, junto a un Senado que no se considera como una Cámara legislativa sino como órgano de apoyo al Rey, con competencias en ámbitos tales como la protección de las garantías individuales y de imprenta, así como en las propias del proceso electoral, son ejemplos de dicha influencia. Lo anterior no quita para que, es evidente, las peculiaridades de aquella España que comenzaba su tortuoso camino hacia la libertad, introdujesen principios e instituciones propias, alejadas del sentir francés.

- En cuanto a nuestra Constitución de 1812, poco más que destacar -además de las importantes discusiones doctrinales referidas a las influencias recibidas por la misma-, el muy importante paralelismo axiológico, institucional y normativo existente entre su texto y el de la Constitución francesa de 1791. Así, los principios de soberanía nacional y su origen popular, junto a la consecuente rigidez que acompaña a ambos textos y la amplitud de los mismos para positivizar los principios e instituciones nuevas que rompen con el Antiguo Régimen.

Igualmente, en el ámbito institucional, ambos textos reconocen al Monarca dentro de un marco de limitación de sus poderes; el monocameralismo como exponente de la nueva legitimidad democrática emergente y enfrentada a la de la Monarquía; la separación estricta de poderes, o el reconocimiento de unos primeros derechos y libertades (bien que en el caso de la Declaración de derechos de 1789, mucho más desarrollados y ordenados que en nuestro texto patrio), exponentes todos ellos básicos para afirmar la defendida influencia. Mucho más si se observan opiniones doctrinales a la luz de una evidente identidad normativa que, sin entrar en otras valoraciones, ponen en valor el argumento que defendemos en este trabajo: una influencia que será criticada o defendida por motivos no tanto constitucionales sino históricos o políticos. 
- El cotejo del Estatuto Real —teniendo en cuenta a estos efectos los diferentes proyectos de reforma-, con las Constituciones francesas de 1814 (sobre todo) y 1830, también evidencia una marcada influencia foránea.

El comienzo de prácticas parlamentarias, la colaboración entre unos poderes regio y parlamentario antes enfrentados y sin relación jurídicoconstitucional posible, la compatibilidad de cargos ministeriales y parlamentarios, no son sino aspectos concretos que especifican igualmente la identidad principial que anima tanto los textos galos citados como el Estatuto Real: acuerdo, más o menos deseado, entre la Corona y las Cortes, el carácter flexible del texto constitucional, su apuesta por una mayor brevedad, por la parlamentarización de las prácticas políticas o por el bicameralismo, inciden igualmente en los textos de uno y otro lado de unos Pirineos que, en este caso, no lo fueron tanto.

$Y$ es que, en efecto, en cuanto a la influencia de las Constituciones francesas en los comienzos del constitucionalismo español, los Pirineos no actuaron como frontera,; antes bien, se configuraron como el verdadero nexo de unión de la España peninsular con una Europa que avanzaba hacia el liberalismo, hacia la libertad.

Title:

"The influence of French Constitutionalism on the phase of Constitutional iniciation in Spain (1808-1834)».

\section{Summary:}

1. CONCEPTUAL AND METHODOLOGICAL INTRODUCTION: SPANISH HISTORICAL CONSTITUTIONALISM 1.1. Constitutional Instability. 1.2. Characteristics of Spanish constitutionalism. 1.2.1. Internal features. 1.2.2. External features. 2. THE STATUTE OF BAYONNE, JULY 6, 1808. 2.1. Introduction. Dogmatic part. 2.2. Institutional organization. 2.2.1. Executive power. 2.2.2. Organs supporting executive power: the Senate and the State Council. 2.2.3. Legislative power. 3. THE POLITICAL CONSTITUTION OF THE SPANISH MONARCHY of MARCH 19, 1812. 3.1. Introduction. Dogmatic part. 3.2. Institutional organization. 3.2.1. Legislative power. 3.2.2. Executive power. 4. THE ROYAL STATUTE OF APRIL 10, 1834. 4.1. Introduction. Dogmatic part. 4.2. Institutional organization. 4.2.1. Executive power. 4.2.2. Legislative power. 5. CONCLUSION. 


\section{Key words:}

Influence of French constitutionalism on Spanish constitutionalism; historic constitutionalism in France; French constitution of 1791; French Napoleonic constitutions; French constitutional charters of 1814 and 1830; historic constitutionalism in Spain: general characterization; Statute of Bayonne of 1808; Spanish constitution of 1812; Royal Statute of 1834; liberalism; national sovereignty.

\section{Abstract:}

The influence of French constitutionalism on the origins of Spanish constitutionalism is evident. The Statute of Bayonne, with a clear Napoleonic influence, brought about the beginning of constitutionalist ideas in Spain, which originated, as in almost all the rest of Europe, in a revolutionary France. Thus, for example, the consideration of the Monarchy as an essential element, the fragmentation of the rest of the institutions with a consequent loss of any possible political weight, or the institutionalization of the Bonaparte family monarchy, along with the fact that the Senate was not considered as a legislative chamber- it was defined as an organ to support the King, with competences in areas such as the protection of individual guarantees and the press, as well as in electoral processes- are examples of this influence. As to the Constitution of 1812, we encounter an obvious axiological, institutional and normative parallelism with the text of the French Constitution of 1791. We thus encounter principles of national sovereignty and its popular origin, along with the consequent rigidity that accompanies both texts and the extent of both in order to develop the new principles and institutions that break with the Old Regime. Both texts recognize the Monarchy within a framework of limited powers; a single chamber as the instrument of a new emerging democratic legitimism and in confrontation with the Monarchy; a strict separation of powers, the appearance of rights and freedoms (this is the case of the Declaration of Rights of 1789, much more developed and organized than in the Spanish text) and these are all basic exponents in order to affirm the defended French influence. And even more so if we observe the doctrinal opinions in the light of an evident normative identity that gives value to the argument defended in this paper: an influence that will be criticized or defended for historical or political motives rather than constitutional ones. The comparison of the Royal Statute- taking into account the effect of different projects of reformwith the French Constitutions of 1814 (above all) and 1830- also show a significant foreign influence. The beginnings of parliamentary practice, 
the collaboration between royal and parliamentary powers previously in confrontation and without a possible legal-constitutional relation, the compatibility of ministerial and parliamentary posts are nothing more than concrete aspects that specify the principal identity underlying both the above-mentioned French texts, as well as the Royal Statute. 